MARCELA SENE ROCHA

Avaliação reprodutiva de ovelhas da raça Texel submetidas a diferentes protocolos de indução de estro na contraestação reprodutiva

São Paulo

2013 


\section{Avaliação reprodutiva de ovelhas da raça Texel submetidas a diferentes protocolos de indução de estro na contraestação}

\section{reprodutiva}

Dissertação apresentada ao Programa de Pós-Graduação em Reprodução Animal da Faculdade de Medicina Veterinária e Zootecnia da Universidade de São Paulo para a obtenção do título de Mestre em Ciências

Departamento:

Reprodução Animal

\section{Área de concentração:}

Reprodução Animal

\section{Orientadora:}

Prof. Dr. Cláudio Alvarenga de Oliveira.

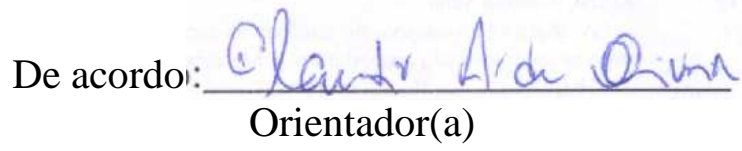

São Paulo 
Autorizo a reprodução parcial ou total desta obra, para fins acadêmicos, desde que citada a fonte.

DADOS INTERNACIONAIS DE CATALOGAÇÃO-NA-PUBLICAÇÃO

(Biblioteca Virginie Buff D’Ápice da Faculdade de Medicina Veterinária e Zootecnia da Universidade de São Paulo)

Rocha, Marcela Sene

Avaliação reprodutiva de ovelhas da raça Texel submetidas a diferentes protocolos de indução de estro na contraestação reprodutiva / Marcela Sene Rocha. -- 2013.

59 f. : il.

Dissertação (Mestrado) - Universidade de São Paulo. Faculdade de Medicina Veterinária e Zootecnia. Departamento de Reprodução Animal, São Paulo, 2014.

Programa de Pós-Graduação: Reprodução Animal.

Área de concentração: Reprodução Animal.

Orientador: Prof. Dr. Cláudio Alvarenga de Oliveira.

1. Ovinos. 2. Reprodução. 3. Progesterona. 4. Estro. I. Título. 


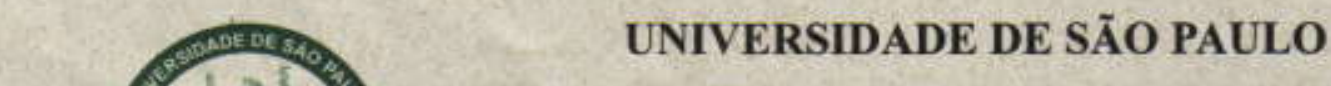

FACULDADE DE MEDICINA VETERINÁRIA E ZOOTECNIA

Comissão de Ética no uso de animais

\section{CERTIFICADO}

Certificamos que o Projeto intitulado "Avaliação do protocolo hormonal de 9 dias em comparação com o de 12 dias utilizando implante de progesterona de primeiro e segundo uso em ovelhas da raça Texel no período de anestro sazonal", protocolado sob o $\mathrm{n}^{\circ}$ 2789/2012, utilizando 292 (duzentos e noventa e dois) ovinos, sob a responsabilidade do(a) Prof. Dr. Claudio Alvarenga de Oliveira, está de acordo com os princípios éticos de experimentação animal da "Comissão de Ética no uso de animais" da Faculdade de Medicina Veterinária e Zootecnia da Universidade de São Paulo e foi aprovado em reunião de 17/10/2012.

We certify that the Research "Hormonal evaluation protocolo $\mathrm{f} 9$ days compared with 12 days of progestin implantation usinf the first and second use of the Texel sheep during the seasonal anoestrus", protocol number 2789/2012, utilizing 292 (two hundred ninety two) ovine, under the responsibility Prof. Dr. Claudio Alvarenga de Oliveira, agree with Ethical Principles in Animal Research adopted by "Ethic Committee in the use of animals" of the School of Veterinary Medicine and Animal Science of University of São Paulo and was approved in the meeting of day $10 / 17 / 2012$.

São Paulo, 18 de outubro de 2012.

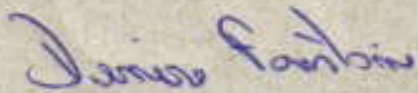

Denise Tabacchi Fantoni

Presidente 


\section{FOLHA DE AVALIAÇÃO}

Autor: ROCHA, Marcela Sene

Título: Avaliação reprodutiva de ovelhas da raça Texel submetidas a diferentes protocolos de indução de estro na contraestação reprodutiva

Dissertação apresentada ao Programa de Pós-Graduação em Reprodução Animal da Faculdade de Medicina Veterinária e Zootecnia da Universidade de São Paulo para obtenção do titulo de Mestre em Ciência

Data:

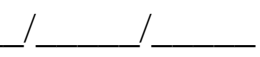

\section{Banca Examinadora}

Prof. Dr.

Instituição: Julgamento:

Prof. Dr.

Instituição:

Julgamento:

Prof. Dr.

Instituição: Julgamento: 


\section{DEDICATÓRIA}

Dedico primeiramente aos meus pais por tudo que fizeram por mim até hoje, por terem me dado todas as condições para que eu pudesse chegar até aqui. Agradeço por todo o apoio, incentivo, confiança e principalmente pela dedicação e amor infinitos que hoje depois de ter aprendido e vivido, posso transmitir para o meu filho.

Dedico também à minha querida Avó Ana que é o meu exemplo de mulher forte, guerreira e possui uma alegria de viver imensa. Foi quem cuidou do meu filho Felipe, quando eu precisei para que pudesse cumprir os meus compromissos.

E por fim dedico esse trabalho a minha colega de laboratório que se tornou uma grande amiga e parceira, Lilian Mara Kirsch Dias, que me ajudou em tudo e pacientemente me passou o seu conhecimento.

Muito obrigada!!!! 


\section{AGRADECIMENTOS}

Agradeço primeiramente ao Prof. Dr. Cláudio Alvarenga de Oliveira pela oportunidade, incentivo e compreensão ao longo do projeto.

Aos meus irmãos, amigos e todos familiares por todo o apoio e torcida.

Ao Prof. Carlos Henrique Brunner por ter me mostrado o caminho para chegar até aqui.

Ao Sebastião Faria, Renato Valentim, Thiago e César Ribeiro da Cabanha CR, Marcílio Nich, Priscila Viau e Patrícia Lopes, que foram pessoas fundamentais para a realização do projeto. À Daniela Magalhães pela companhia no PAE.

Às empresas Tecnopec, Chison Kylumax e DMS.

Aos Profs. do Departamento de Reprodução Animal (VRA) e outros departamentos da FMVZ-USP que contribuíram para a minha formação.

À Harumi por me ajudar em tudo que foi necessário e deixar as coisas sempre mais fáceis do que pareciam.

Agradeço a Roberta e a Thaís que sempre ajudaram com tanta gentileza.

À Elza bibliotecária pela ajuda na correria da reta final do mestrado.

A todos os funcionários da FMVZ-USP.

À Coordenação de Aperfeiçoamento de Pessoal de Nível Superior (Capes) pela bolsa de estudos.

E por fim, um agradecimento mais que especial ao meu companheiro Luiz Brito e ao meu filho, Felipe por me mostrar que a vida pode ser sempre melhor e mais divertida a cada dia.

Muito obrigada!!!!! 


\section{RESUMO}

ROCHA, M. S. Avaliação reprodutiva de ovelhas da raça Texel submetidas a diferentes protocolos de indução de estro na contraestação reprodutiva. [Reproductive evaluation of Texel ewes submitted to different protocols to induce estrous during non-breeding season]. 2014. 59 f. Dissertação (Mestrado em Ciências) - Faculdade de Medicina Veterinária e Zootecnia, Universidade de São Paulo, São Paulo, 2013.

Para estudo de diferentes períodos de protocolos de indução do estro e de um novo dispositivo de progesterona para pequenos ruminantes (DPR - Tecnopec, Brasil) foram realizados dois experimentos em ovelhas da raça Texel durante a contraestação reprodutiva. Experimento 1: com o objetivo de comparar a eficiência de protocolos de indução do estro em períodos de nove versus doze dias e com a utilização de dispositivos novos versus usados através das taxas de gestação e manifestação de estro, foram utilizados 160 ovelhas Texel. Os animais foram divididos aleatoriamente em 4 grupos: protocolo de 9 dias com a utilização de um dispositivo feito em silicone novo ( $\mathrm{G} 9 \mathrm{~N}, \mathrm{n}=91)$, protocolo de 9 dias com a utilização de dispositivo usado (G9U, $\mathrm{n}=25$ ), protocolo de 12 dias com a utilização de dispositivo novo (G12N, n=26) e protocolo de 12 dias com a utilização de dispositivo usado (G12U, n=18). Os dispositivos foram colocados no dia zero (D0) e retirados no dia nove (D9) nos grupos G9N e G9U e doze dias após (D12) nos grupos G12N e G12U. Junto com a aplicação de 0,125mg de cloprostenol (Estron, Agener, Brasil) e 500UI de eCG (Folligon ${ }^{\circledR}$, Intervet, Netherland). Experimento 2: com o objetivo de comparar o Dispositivo Pequenos Ruminantes (DPR Tecnopec, Brasil) versus esponja impregnada com medroxiprogesterona Progespon® (MSD, Brasil) no protocolo de 9 dias foram utilizadas 152 ovelhas Texel. Os animais foram divididos aleatoriamente em 2 grupos: protocolo de 9 dias com a utilização da esponja Progespon® (GP, n=61) e protocolo de 9 dias com a utilização do Dispositivo Pequenos Ruminantes (GDPR, $n=91$ ). O protocolo utilizado foi semelhante ao G9N do experimento 1 exceto pelo tipo de dispositivo utilizado. No experimento 1 e 2 as variáveis analisadas foram: taxas de manifestação de estro, concepção e prenhez e dispersão no intervalo de cio. O exame de ultrassonografia para detecção de prenhez (Chisson, KYLUMAX) foi realizado com 30 e 60 dias da retirada do dispositivo. O delineamento utilizado foi inteiramente casualizado e os dados analisados através do programa SAS System for Windows (SAS, 2000). Como resultados observou-se que não houve diferenças entre os protocolos de 9 e 12 dias, assim como entre os dois tipos de dispositivos em relação a taxa de manifestação de estro, concepção e prenhez. Houve maior taxa de manifestação de estro $(\mathrm{P}<0,05))$ do dispositivo 
novo se comparado com o usado. Foi observado menor $(\mathrm{P}<0,05)$ dispersão na ocorrência de estro no protocolo de 9 dias utilizando o dispositivo novo. Conclui-se que os protocolos de 9 e 12 dias e ambos dispositivos são semelhantes quanto a eficácia de indução do estro em ovelhas Texel durante a contraestação reprodutiva e que o dispositivo novo apresenta maior taxa na manifestação de estro em comparação com o dispositivo usado.

Palavras-chave: Ovinos. Reprodução. Progesterona. Estro. 


\begin{abstract}
ROCHA, M. S. Reproductive evaluation of Texel ewes submitted to different protocols to induce estrous during non-breeding season. [Avaliação reprodutiva de ovelhas da raça Texel submetidas a diferentes protocolos de indução de estro na contraestação reprodutiva]. 2014. 59 f. Dissertação (Mestrado em Ciências) - Faculdade de Medicina Veterinária e Zootecnia, Universidade de São Paulo, São Paulo, 2013.
\end{abstract}

Two experiments were conducted to study different periods of estrus induction and study of a new progesterone device for small ruminants (DPR - Tecnopec, Brazil) protocols in Texel ewes during the non-breeding season. Experiment 1: 160 Texel ewes were used in order to compare the efficiency of estrus induction protocols with the nine versus twelve days periods and the use of new versus used devices through the rates of estrus manifestation and pregnancy. The animals were randomly divided into 4 groups: 9 days protocol with the use of the new device $(\mathrm{G} 9 \mathrm{~N}, \mathrm{n}=91)$ and 9 days protocol with the use of used devices $(\mathrm{G} 9 \mathrm{U}, \mathrm{n}=25)$ 12 days protocol with the use of the new device $(\mathrm{G} 12 \mathrm{~N}, \mathrm{n}=26)$ and 12 days protocol with use of used device (G12U, $\mathrm{n}=18$ ). The devices were placed on day zero (D0) and removed on day nine (D9) in the G9N and G9U groups and twelve days after (D12) in the groups G12U and G12N, together with the use of $0.125 \mathrm{mg}$ of cloprostenol (Estron, Agener, Brazil) and 500 IU of eCG (Folligon ${ }^{\circledR}$, Intervet, Netherland). Experiment 2: 152 Texel ewes were used in order to compare the Small Ruminants Device (DPR - Tecnopec, Brazil) versus Sponge impregnated with medroxyprogesterone Progespon ${ }^{\circledR}$ (MSD, Brazil) in the 9 days protocol. The animals were randomly divided into 2 groups: 9 days protocol using sponge Progespon® $(\mathrm{GP}, \mathrm{n}=61)$ and 9 days protocol using Small Ruminants Device (GDPR, $\mathrm{n}=91$ ). The protocol used was similar to that G9N of experiment 1 except by the type of device used. 312 sheep were used in the period of September to November 2012. The considered methodologies in experiment 1 were: rates of estrus manifestation, conception and pregnancy and dispersion in the heat interval. The ultrasound examination for detection of pregnancy (Chisson, KYLUMAX) was performed at 30 and 60 days after D9 and D12. The experimental design was completely randomized and analyzed using the SAS System for Windows (SAS, 2000) program. As results it was shown no differences between the protocols 9 and 12 days, as well as between the two types of devices in relation to the estrus manifestation, conception and pregnancy rate. There was a higher estrus manifestation rate $(\mathrm{P}<0.05)$ of the new device compared with the used one. It was observed lower $(\mathrm{P}<0.05)$ dispersion in the occurrence of estrus in the 9 days protocol. We conclude that the protocols 9 and 12 days and both devices 
are similar in efficacy to induce estrus in Texel ewes during the non-breeding season and the new device has the highest rate of estrus manifestation compared to the used device.

Keywords: Ovine. Reproduction. Progesterone. Estrous. 


\section{LISTA DE FIGURAS}

Figura 1 - Rebanho de ovelhas da raça Texel............................................................... 25

Figura 2 - Inter-relações no controle da função reprodutiva da fêmea

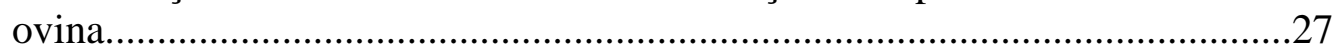

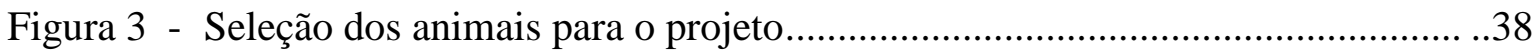

Figura 4 - Aplicação da mistura de tinta em pó e óleo na região do esterno do reprodutor

Figura 5 - Ovelhas marcadas após a monta 


\section{LISTA DE TABELAS}

Tabela 1 - Taxas de manifestação de estro, concepção e prenhez de ovelhas submetidas a protocolo de indução do estro com uso do Dispositivo Pequenos Ruminantes (DPR Tecnopec, Brasil) utilizado por 9 dias novo e usado e 12 dias novo e usado. 45

Tabela 2 - Dispersão de cio em relação aos protocolos de 9 versus 12 dias, DPR novo versus usado e DPR versus Progespon®...... .46

Tabela 3 - Taxas de manifestação de estro, concepção e prenhez de ovelhas submetidas a protocolo de indução do estro de 9 dias utilizando Progespon® (MSD, Brasil) versus Dispositivo Pequenos Ruminantes (DPR - Tecnopec, Brasil). 
LISTA DE ABREVIATURAS E SIGLAS

CL corpo lúteo

eCG gonadotrofina coriônica equina

FSH hormônio folículo estimulante

GnRH hormônio liberador de gonadotrofinas

LH hormônio luteinizante

$\mathrm{PGF}^{2} \alpha \quad$ prostaglandina $\mathrm{F}^{2} \alpha$ 


\section{SUMÁRIO}

1 INTRODUÇÃO .......................................................................................................22

2 REVISÃO DE LITERATURA..................................................................................24

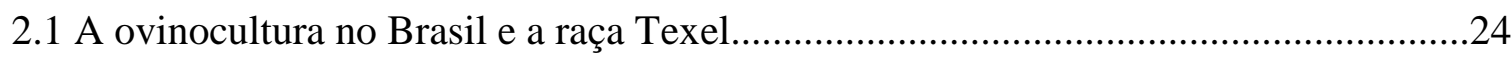

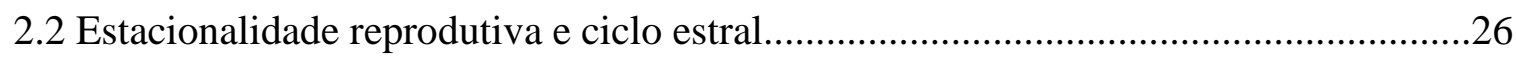

2.3 Métodos para indução do estro e da ovulação..........................................................29

2.3.1 Protocolos hormonais a base de progesterona................................................30

2.3.2 Gonadotrofina Coriônica Equina (eCG).......................................................32

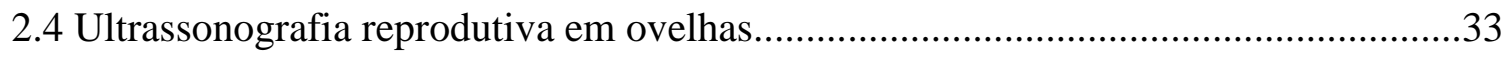

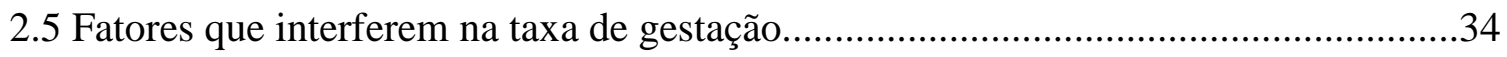

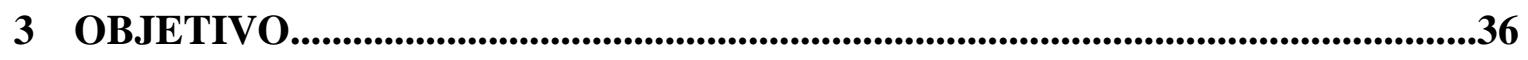

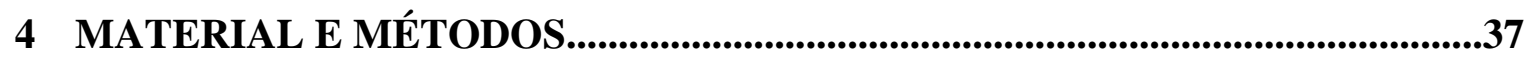

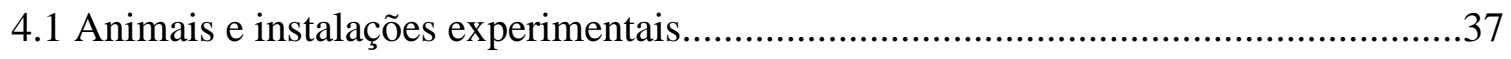

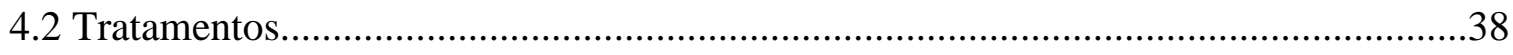

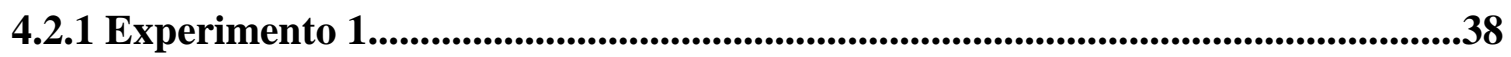

4.2.2 Experimento 2...............................................................................................................................39

4.3 Manejo de monta e observação de estro.................................................................40

4.4 Exames ultrassonográficos para detecção de prenhez.................................................41

4.5 Colheitas de sangue para dosagem de progesterona..............................................42

4.6 Análise da progesterona por radioimunoensaio (RIE) …................................... 42

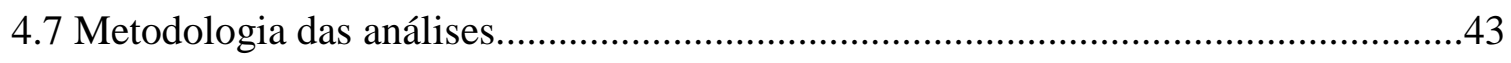

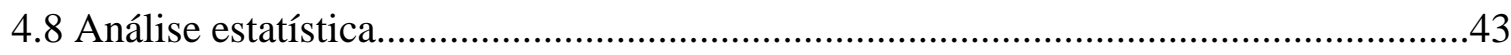

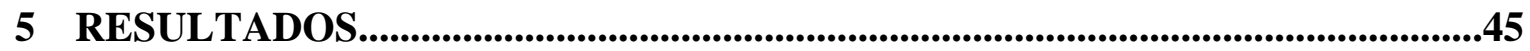

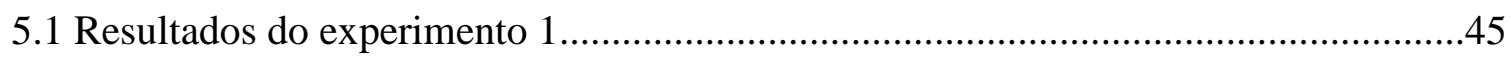




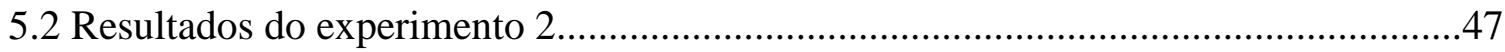

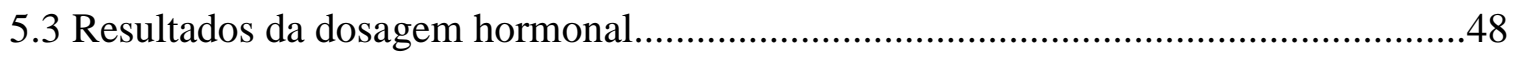

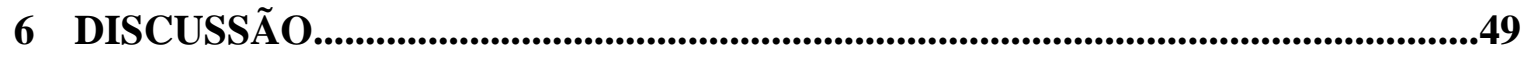

7 CONCLUSÃO

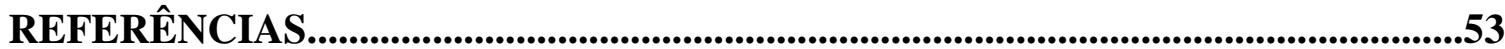




\section{INTRODUÇÃO}

O Brasil possui plenas condições de tornar-se exportador de carne ovina a exemplo do que já ocorre com bovinos, suínos e aves. Um dos principais entraves para o desenvolvimento da ovinocultura no país é a incapacidade em atender às necessidades do mercado consumidor que exige uma produção em escala, homogênea e de qualidade. Essas exigências podem ser alcançadas através de investimentos em biotecnologias da reprodução como o aprimoramento do uso dos protocolos hormonais de sincronização do estro.

Diante da necessidade da produção de carne de cordeiro com alta qualidade de carcaça, o Texel se mostra como uma ótima opção dentre as raças especializadas para produção de carne. É um ovino lanado, de tamanho médio, musculatura forte e arredondada além de ser extremamente rústico (http://www.aspaco.com.br/raças/texel). As ovelhas lanadas especializadas para a produção de carne como a raça Texel apresentam épocas marcantes de anestro estacional. As suas atividades cíclicas reprodutivas são interrompidas a partir do mês de Agosto quando a luminosidade é crescente, fazendo com que a produção de cordeiros fique restrita a uma determinada época do ano (SASA et al., 2002; SANTOS et al., 2011).

O uso de dispositivos intravaginais impregnados com progesterona é um método amplamente utilizado para a sincronização e indução de estro, porém, um dos principais problemas relacionados aos protocolos hormonais é a grande variação de resultados alcançados (FIERRO et al., 2013). Na literatura há uma tendência na diminuição do período de manutenção do progestágeno (UNGERFELD; RUBIANES, 1999; FONSECA et al., 2005; MARTEMUCCI; D'ALESSANDRO, 2011; PIETROSKI et al., 2013), tradicionalmente utilizados por 12 a 14 dias (LEYVA et al., 1998), o que permite maior concentração do manejo reprodutivo e melhor aproveitamento dos dispositivos de progesterona, possibilitando sua reutilização (VILARINO et al., 2010; DIAS et al., 2012, 2013).

Diante desses relatos, justifica-se a realização de estudos visando à implementação de protocolos de indução e sincronização de estro apropriados para raças de ovinos estacionais especializados para a produção de carne que irão melhorar de forma consistente o fornecimento de produtos em escala e de qualidade.

O objetivo deste trabalho foi comparar dois períodos de protocolos de indução do estro de 9 versus 12 dias, avaliar a eficácia de um novo dispositivo feito em silicone impregnado com progesterona Dispositivo Pequenos Ruminantes (DPR - Tecnopec, Brasil) utilizado pela primeira e 
segunda vez e comparar o DPR versus um dispositivo feito em esponja e impregnado com medroxiprogesterona Progespon® (MSD, Brasil), já conhecido no mercado.

As hipóteses deste trabalho são que os diferentes períodos de protocolo hormonal, o Dispositivo Pequenos Ruminantes (DPR - Tecnopec, Brasil) novo e usado e este em comparação com o dispositivo feito em esponja Progespon ${ }^{\circledR}$ (MSD, Brasil) apresentem resultados semelhantes em relação as taxas de manifestação de cio, concepção e prenhez e dispersão de cio. 


\section{REVISÃO DE LITERATURA}

\subsection{A ovinocultura no Brasil e a raça Texel}

A ovinocultura está presente em praticamente todos os continentes, a ampla difusão da espécie se deve principalmente ao seu poder de adaptação a diferentes climas, relevos e vegetações (VIANA, 2008). De acordo com o Anualpec (2012), o rebanho de ovinos no Brasil vem aumento a cada ano, somando um rebanho de 17,38 milhões de cabeças. Contudo, o consumo de carne ovina pelos brasileiros ainda é restrito em comparação com outras espécies (VIANA; REVILLION; SILVEIRA, 2013).

De acordo com o informativo semanal do indicador de preço do cordeiro paulista $n^{\circ} 124$ (UNICETEX/USP), no período de Março a Abril de 2013, o preço do cordeiro na região de São José dos Campos esteve a $\mathrm{R} \$ 5,20 \mathrm{~kg} / \mathrm{vivo,}$ encontrando o maior valor na região de Marília ( $\mathrm{R} \$ 5,60 \mathrm{~kg} / \mathrm{vivo}$ ) e o menor na região de Campinas ( $\mathrm{R} \$ 4,72 \mathrm{~kg} / \mathrm{vivo}$ ). Eyerkauferl, Costa e Faria (2007), realizando um levantamento dos custos de produção de uma cabanha destinada à produção de carne no estado do Rio Grande do Sul, concluíram que o custo de produção do cordeiro ficou em $\mathrm{R} \$ 3,50$ por quilo de carne produzida, apurados pelo método do custeio variável.

A sazonalidade produtiva da atividade, a inexistência de um mercado constante, a exigência de uma oferta regular de animais, a necessidade de escala para comercialização e a busca por animais de qualidade por parte dos frigoríficos são dificuldades encontradas na atividade (VIANA; SILVEIRA, 2009).

Diante da necessidade da produção de carne de cordeiro com alta qualidade de carcaça, o Texel se mostra como uma ótima opção dentre as raças especializadas para produção de carne. É um ovino lanado, de tamanho médio e musculatura forte e arredondada (Figura 1). Sua origem se deu na Holanda, especificamente na Ilha de Texel, quando um grupo de ovinocultores locais que passavam por um período de escassez de alimento para os animais, decidiram promover um trabalho de melhoramento genético nos ovinos situados na ilha, tendo como resultado o Texel que conhecemos hoje. Por esta razão, é um animal de alta 
rusticidade em sistemas extensivos e precoce em regime de pastagem (http://www.aspaco.com.br/raças/texel).

Figura 1 - Rebanho de ovelhas da raça Texel

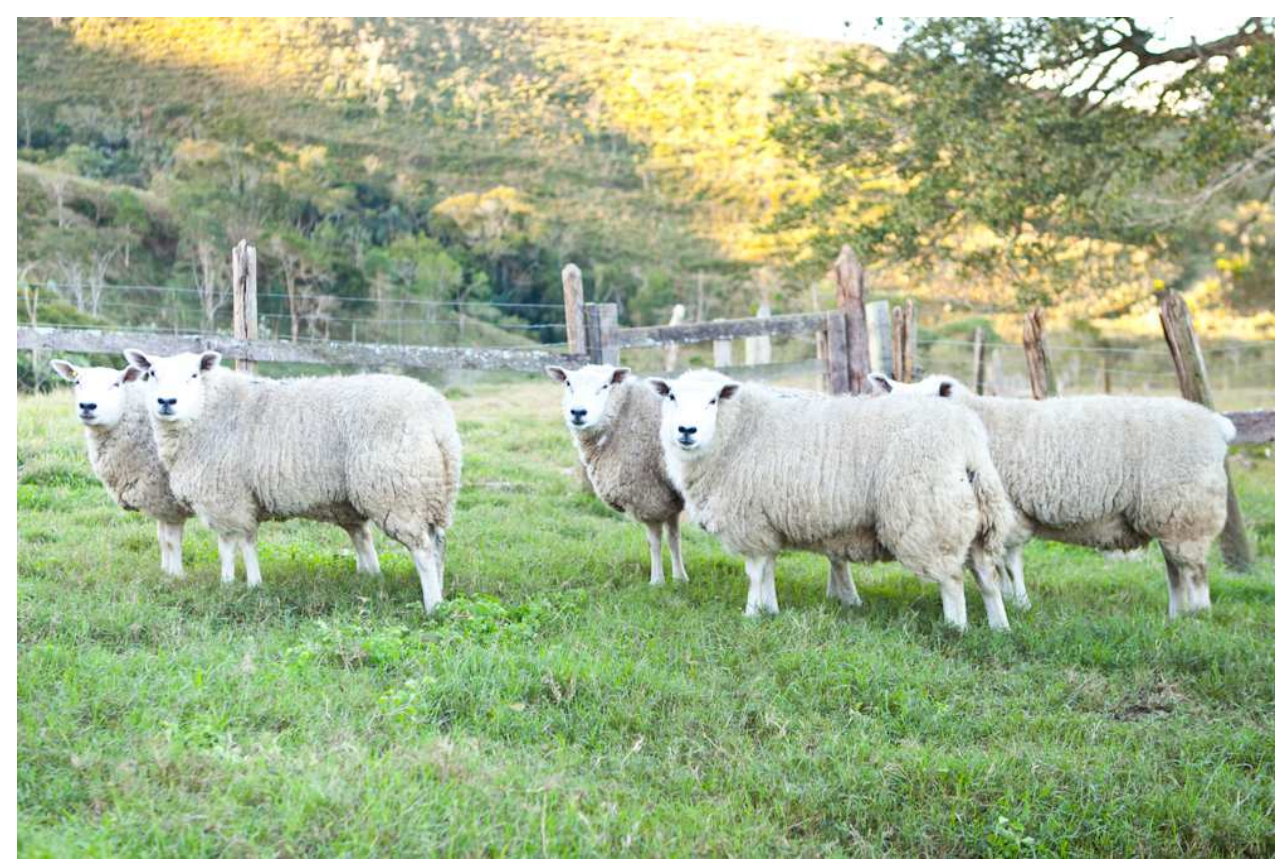

Fonte: (ROCHA, M. S., 2013).

De acordo com Pinheiro, Silva Sobrinho e Andrade (2009), o cruzamento industrial entre raças especializadas para produção de carne pode ser uma alternativa para melhorar as características da carcaça ovina. Villaroel et al. (2006), afirmam que a utilização de carneiros da raça Texel sobre fêmeas deslanadas SRD resulta em maiores ganhos de peso de suas crias, quando comparado com as da raça Santa Inês puras, raça esta, deslanada, predominante na região Nordeste do Brasil (GARCIA; PEREZ; OLIVEIRA, 2000 ).

Fato também observado por Furusho-Garcia et al. (2004), que ao realizarem cruzamentos com a raça Santa Inês observaram uma superioridade nos animais cruzados com a raça Texel com melhor desempenho em comparação aos animais Santa Inês puros. 


\subsection{Estacionalidade reprodutiva e ciclo estral}

A maioria das raças de ovinos possui um modelo de reprodução sazonal de acordo com a época do ano, apresentando períodos de atividade estral predominantemente no outono e inverno, quando a luminosidade é decrescente, alternado com períodos de anestro estacional na contraestação reprodutiva, quando a luminosidade é crescente (SASA et al., 2002; HAFEZ; HAFEZ, 2004). Segundo Fonseca (2005), a duração desta estação é definida primariamente pela latitude e secundariamente pela raça. Assim, quanto mais longe da linha do Equador, onde existe grande variação da luminosidade diária ao longo do ano, a estacionalidade reprodutiva tende a ser mais evidente, entretanto, em latitudes mais baixas, com pouca ou nenhuma variação da luminosidade ao longo do ano, a estacionalidade reprodutiva tende a diminuir ou mesmo cessar.

Em mamíferos, o hormônio responsável por mediar a regulação dos ritmos sazonais por meio do fotoperíodo é a melatonina (VANECEK, 1998). A melatonina é o neurotransmissor responsável por mediar as informações diárias do ciclo de luz-escuridão, informando ao organismo a duração da noite e, consequentemente, o período do ano correspondente. A presença de seus receptores em células hipotalâmicas e células gonadotróficas da hipófise explicam os efeitos da melatonina na secreção das gonadotrofinas (LH e FSH) e na organização dos ritmos sazonais (MALPAUX et al., 2001; ROCHA et al., 2011).

É possível observar grande diferença entre as raças lanadas, que apresentam épocas marcantes de anestro estacional e as deslanadas, que podem ciclar ao longo de todo o ano (SANTOS et al., 2011). Um estudo realizado por Sasa et al. (2002), revelou que ovelhas lanadas tiveram as atividades cíclicas reprodutivas interrompidas a partir do mês de Agosto, enquanto que fêmeas deslanadas não apresentaram estacionalidade reprodutiva.

A manifestação de cio nas fêmeas ovinas tem duração média de 30 horas e o intervalo entre os estros pode ser de 14 a 19 dias, com média de 17 dias. O ciclo estral compreende duas fases distintas: a fase lútea com duração de 14 a 17 dias caracterizada pela predominância de progesterona, e a fase de crescimento folicular com duração de 3 dias com predominância do estrógeno (PUGH, 2005).

O ciclo estral é caracterizado por uma sequência de eventos endócrinos relacionados entre si a partir do hipotálamo (Figura 1). O sistema nervoso central, por ação do hormônio liberador de gonadotrofinas $(\mathrm{GnRH})$, estimula a adenohipófise à síntese e secreção dos hormônios luteinizante (LH) e folículo estimulante (FSH). Essas gonadotrofinas hipofisárias 
estimulam os ovários à esteroidogênese dos hormônios progesterona e estrógeno e junto a estes promovem o desenvolvimento dos folículos ovarianos e à ovulação (SCARAMUZZI; ADAMS; BARD, 1993).

Figura 2 - Inter-relações no controle da função reprodutiva da fêmea ovina

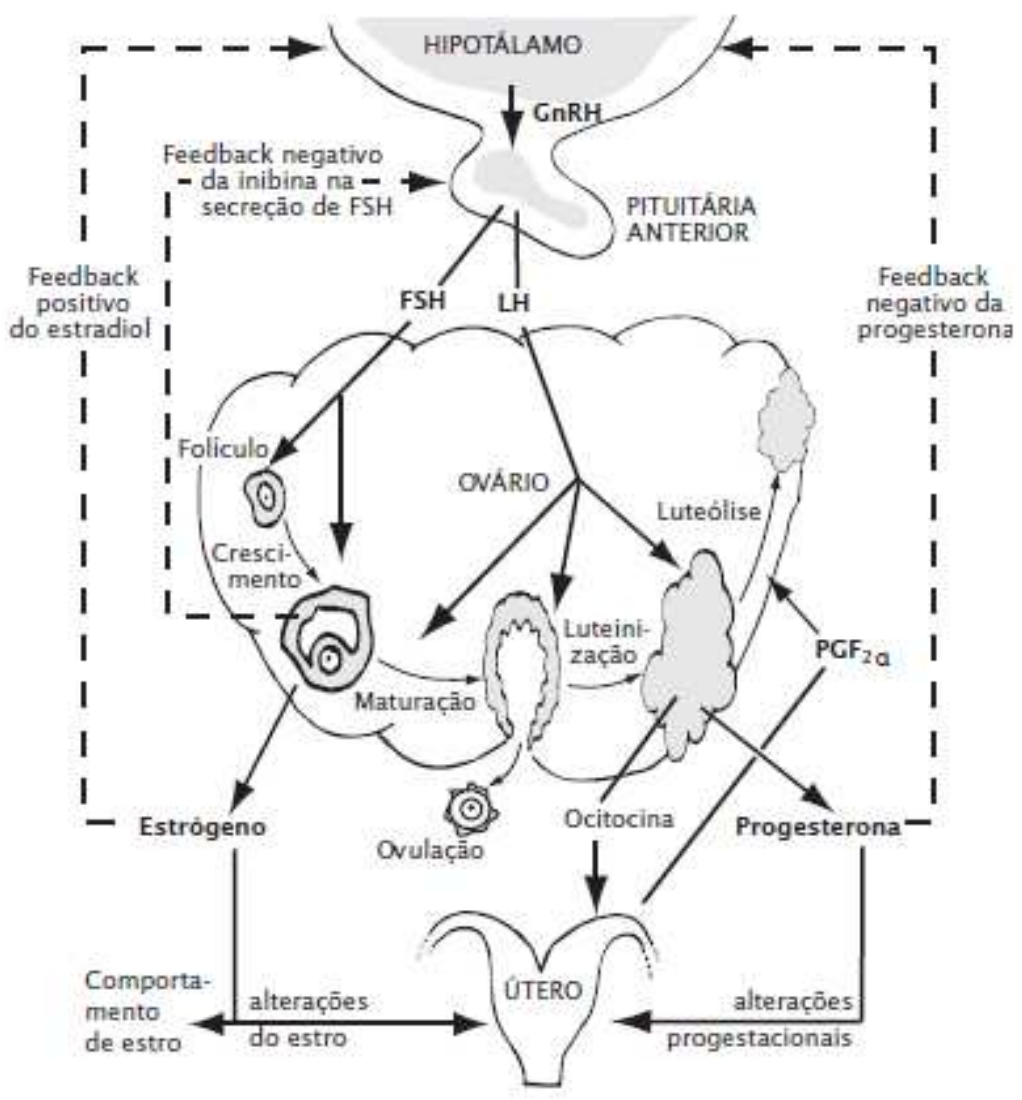

Fonte: (INTERVET, [200-]).

O crescimento folicular na ovelha é um processo lento, fazendo com que um folículo primordial se torne ovulatório (CAHILL, 1981). Nos estágios iniciais de desenvolvimento, os folículos possuem receptores de FSH e LH encontrados nas células da granulosa e teca, respectivamente, porém, não são dependentes de gonadotrofinas, mas influenciados por fatores parácrinos e autócrinos (FINDLAY et al., 2000). Os folículos se tornam sensíveis a ação das gonadotrofinas no estágio de formação do antro, apresentando diâmetros nessa fase que variam de 0,8 a 2,5 milímetros (DOWING; SCARAMUZZI, 1991). Nessa etapa inicia-se a atividade da aromatase, enzima responsável pela síntese de andrógenos, um fator importante 
no desenvolvimento folicular. $\mathrm{O}$ aumento da atividade da aromatase aumenta a sensibilidade das células da granulosa ao FSH (SCARAMUZZI et al., 1993). Com um suporte adequado de FSH a atividade da aromatase é aumentada e os folículos secretam mais estradiol (VINÕLES et al., 2001). Porém, com um suprimento deficiente de FSH, a atividade da aromatase não é mantida, diminuindo a secreção de estradiol e um acúmulo excessivo de andrógenos no interior do folículo, levando a atresia (SCARAMUZZI et al., 1993). Os folículos dominantes ou ovulatórios possuem diâmetro maior que $4 \mathrm{~mm}$ e habilidade de passar aos estágios finais de maturação sem sofrer atresia (DRIANCOURT, 1994).

Estes estágios de crescimento folicular que acontecem de maneira organizada e cíclica são chamados de ondas de crescimento folicular (EVANS et al., 2000). Durante a fase luteínica do ciclo estral é observado um corpo lúteo resultante do rompimento de um folículo ovulatório e consequente liberação do oócito. O corpo lúteo é responsável por produzir e secretar progesterona, que atinge a maior concentração 10 dias após a ovulação e se mantém até a luteólise (GOODMAN et al., 1981). A secreção de FSH é controlada pela secreção de estradiol e inibina que suprime a secreção do FSH, fazendo com que os folículos dominantes passem a responder ao LH e que cresçam e sobrevivam mesmo com baixas concentrações de FSH (McNEILLY et al., 1991). Os altos níveis de progesterona mantêm a frequência de secreção de LH baixa devido o feedback negativo no hipotálamo inibindo o GnRH. Os folículos dominantes não ovulam devido a insuficiente concentração de estradiol para induzir um pico de LH, inicia-se então, a emergência de uma nova onda folicular. Após a luteólise, os níveis de progesterona diminuem, não causando mais a inibição da frequência dos pulsos de LH (GOODMAN et al., 1981). O aumento da concentração de LH causa por consequência um aumento na secreção de esteroides ovarianos. O aumento dos níveis de estradiol durante a fase folicular diminui as concentrações de FSH o que previne o crescimento e maturação de outros folículos (CAMPBELL et al., 1990). Na ovelha, o pico de LH ocorre aproximadamente 4 a 8 horas após o início do cio e a ovulação ocorre aproximadamente 24 horas após o pico do LH (SOUZA, 1993).

Durante o período de anestro estacional é observado uma redução de secreção pulsátil de GnRH a partir do cérebro, em parte por causa de um aumento na atividade de feedback negativo do estrógeno (SMITH, 2012). Durante esse período, o LH é secretado com menos frequência, o que resulta na ausência de estro e ovulação (KAYA et al., 2013) em virtude da falha dos folículos antrais em crescer e maturar, como normalmente ocorre na fase préovulatória do ciclo estral (O’Callaghan et al., 2000). Porém, o desenvolvimento folicular 
ovariano das ovelhas que ocorre como padrão de três ondas no período de estro, não é interrompido durante a temporada de anestro estacional (AMIRIDIS; CSEH, 2012).

De acordo com Hunter (1991), ciclos ovarianos curtos podem ser observados em ovelhas no início da estação de monta, associados com a luteinização insuficiente que ocorre no corpo lúteo (CL) de ovelhas no momento das mudanças no padrão da função ovariana de anovulatória para ovulatória. Ocorre na estação de transição e início da estação de acasalamento, o que se denomina de regressão luteal precoce. Fenômeno associado a baixas concentrações de progesterona entre o terceiro e sexto dia do ciclo estral (estro $=$ dia 0 ), notando-se um decréscimo na resposta ovulatória e na taxa de gestação de animais acasalados no início da estação reprodutiva (FONSECA, 2005).

2.3 Métodos para indução do estro e da ovulação

Métodos capazes de controlar o ciclo estral, sincronizar o estro e induzir a ovulação são classificados em duas categorias principais: naturais e farmacológicos. Os naturais tem custo reduzido, porém não provocam o estro nem a ovulação com precisão e sua aplicação é mais restrita a determinadas épocas do ano. (DIAS; VILLARROEL; FREITAS, 2000) Pode-se citar como métodos naturais: programas de luz artificial, submetendo as fêmeas a dezesseis horas de luz e oito de escuro durante 60 dias e efeito macho que consiste no afastamento temporário entre as fêmeas e o reprodutor (FONSECA, 2005). Os farmacológicos como implantes de melatonina e protocolos para indução e sincronização do estro são mais eficientes para sincronizar e induzir o estro, permitindo assim, predeterminar o tempo da inseminação artificial (DIAS; VILLARROEL; FREITAS, 2000).

Resultados de taxa de prenhez após a utilização de protocolo de sincronização e indução de cio com a associação de progesterona e eCG durante o período da contraestação em ovelhas lanadas foram de 36\% (SANTOS et al., 2011) e 41,2\% (DOGAN; NUR, 2006). Santos et al. (2011), comparando protocolo hormonal entre ovelhas lanadas e deslanadas obtiveram taxas de apresentação de estro e de prenhez respectivamente de 84,0 e 36,0\% resultantes da sincronização em ovelhas lanadas e de 87,0 e 56,6\% em ovelhas deslanadas.

Oliveira-Muzante et al. (2011), compararam um protocolo hormonal a base de duas aplicações de prostaglandina com intervalo de 7 dias (Synchrovine®) com um protocolo de 
13 dias que associou implante de progesterona com eCG. O resultado de fertilidade observado foi de $26 \%$ para o Synchrovine ${ }^{\circledR}$ e $48 \%$ para progesterona com eCG. Segundo o autor, independente da condição seminal, tempo ou local de inseminação o protocolo convencional de progesterona e eCG apresentará melhores resultados.

De acordo com Fierro et al. (2013), protocolos a base de prostaglandinas podem ser uma boa alternativa para a sincronização de estro no período de ciclicidade reprodutiva, porém quando a ovelha se encontra em anestro estacional não é possível induzir a ovulação utilizando esse medicamento.

\subsubsection{Protocolos hormonais a base de progesterona}

Quanto à estrutura e tipo de progesterona ou progestágeno, os dispositivos mais utilizados em ovinos são em forma de implantes plásticos cobertos por fina camada de silicone e impregnados por progesterona (CIDR® - Pfizer; WHEATON et al., 1993) e esponjas impregnados por fluorgestona (FGA) (GASTON-PARRY et al., 1988) ou acetato de medroxiprogesterona (MAP).

A sincronização da ovulação em ovelhas realizada com a utilização de dispositivos intravaginais impregnados com progestágenos é um método muito utilizado para a sincronização de estro, e seu uso se estende a outras técnicas de reprodução como no caso de superovulação e transferência de embrião (GONZALES-BULNES et al., 2005). As principais vantagens na utilização desses dispositivos são a disponibilidade no mercado e simplicidade de execução (CONTRERAS-SOLIS et al., 2009).

O tratamento com progestágenos, seguido por aplicações de GnRH durante o período de anestro resulta em desenvolvimento folicular, ovulação e função lútea semelhantes às de ovelhas no período de ciclicidade (KAYA et al., 2013).

Dias et al., (2012) utilizando um dispositivo de progesterona novo e usado constatou em ovelhas ovariectomizadas que após a utilização do dispositivo novo, a concentração liberada de progesterona é semelhante à encontrada na situação fisiológica de atividade estral, apresentando no D9 após a colocação do dispositivo 7,33 ng/ml de progesterona. Já no caso do dispositivo usado a concentração encontrada é de $2,5 \mathrm{ng} / \mathrm{ml}$. 
Vilariño, Rubianes e Menchaca (2011), avaliaram dispositivo intravaginal de progesterona (CIDR-G®) utilizado por três vezes em protocolos de indução de estro de 5 dias. As maiores concentrações de progesterona séricas foram encontradas no D0, 12 horas após a inserção do dispositivo com valores de $19 \mathrm{ng} / \mathrm{ml}, 10,3 \mathrm{ng} / \mathrm{ml}$ e 7,7 ng/ml para o CIDR-G® de primeiro, segundo e terceiro uso respectivamente. Depois disso, as concentrações de progesterona diminuíram em todos os grupos e no momento da retirada do dispositivo, as concentrações foram de $9,8 \mathrm{ng} / \mathrm{ml}, 5,9 \mathrm{ng} / \mathrm{ml}$ e $4,5 \mathrm{ng} / \mathrm{ml}$ para o CIDR-G® de primeiro, segundo e terceiro uso respectivamente. A presença dos sinais de estro foram semelhantes em todos os grupos, porém, os valores de progesterona sérica foram maiores no grupo do dispositivo de primeiro uso em comparação aos outros grupos e uma maior taxa de prenhez foi observada no grupo que utilizou o CIDR-G® pela primeira vez com 75,3\% e taxas de $67,4 \%$ e $62,1 \%$ para os grupos de CIDR-G® de segundo e terceiro uso respectivamente. Concentrações elevadas de progesterona sérica resultam no surgimento de uma nova onda folicular. No presente estudo, o uso do dispositivo de primeiro uso foi seguido por ovulação a partir de uma nova onda folicular em 100\% dos casos, diferente dos outros dois grupos em que essa situação ocorreu em $80 \%$ dos animais, que ovularam a partir de folículos mais velhos, o que poderia ser associado com menor fertilidade.

Vilariño et al. (2010), compararam dois tipos diferentes de dispositivos intravaginais, um novo dispositivo DICO® e o CIDR-G® em ovelhas ovariectomizadas. As máximas concentrações séricas de progesterona do DICO $®$ versus CIDR-G® encontradas foram respectivamente de 19,2 e 18,9 nmol/L após 2 horas da inserção dos implantes. Esses permaneceram por 14 dias e as concentrações médias encontradas no momento da retirada foram de 5,9 e 6,4 nmol/L para o DICO® e CIDR-G® respectivamente. Aferiram também a concentração sérica de progesterona em ovelhas ovariectomizadas após a reutilização do DICO ${ }^{\circledR}$ em protocolos de 6 dias de duração. Após 2 horas da inserção dos dispositivos as concentrações foram de 10,8 e $24,1 \mathrm{ng} / \mathrm{ml}$ para o reutilizado e o novo respectivamente. No momento da retirada do dispositivo, a diferença foi de 7,1 e 11,6 ng/ml. Segundo o autor, concentrações acima de $1 \mathrm{ng} / \mathrm{ml}$ são capazes de bloquear ou controlar a pulsatilidade do LH e ovulação em ovelhas. Neste estudo, a vida útil dos folículos ovarianos usando protocolo de 14 dias foi de cerca de 10 dias para o DICO® e o CIDR-G®, podendo considerar o tratamento demasiadamente longo, já que no ciclo natural, os folículos ovulatórios ovulam de 7 a 8 dias após a emergência do folículo (VINÕLES et al., 1999).

Cox et al. (2012), avaliaram a eficácia do implante de progesterona CIDR novo e reutilizado no período de anestro estacional. Os níveis de progesterona sérica nos animais que 
utilizaram CIDR novo se mantiveram mais elevados durante todo o tratamento em comparação ao grupo que utilizou CIDR reutilizado e 97,5\% dos animais dos dois grupos, apresentaram sinais de estro após a remoção do dispositivo novo e usado.

Castilho et al. (2013), compararam protocolos hormonais utilizando dispositivo de progesterona por 14 e 9 dias em ovelhas lanadas obtendo como resultados de manifestação de estro (69,6\% e 80\%), prenhez (34,8\% e 44\%) e concepção (50\% e 55\%) respectivamente.

Segundo Vinõles et al. (2001), a utilização de protocolos de curta duração teriam a vantagem de causar ovulações com folículos mais jovens, atribuindo a isso bons resultados das taxas de fertilidade (87\% de prenhez) em comparação aos longos (63\% de prenhez). Bicudo e Sousa (2002) observaram uma menor dispersão no intervalo de cio para o protocolo de curta duração de 6 dias em comparação ao protocolo longo de 14 dias.

\subsubsection{Gonadotrofina Coriônica Equina (eCG)}

A gonadotrofina coriônica equina $(\mathrm{eCG})$ é produzida pelo endométrio das fêmeas eqüinas entre os dias 40 e 130 de gestação. Quando aplicado em outras espécies, apresenta atividade semelhante ao FSH (80\%), mas também alguma atividade de LH (20\%) (BARRET et al., 2004) e apresenta meia vida de aproximadamente 46 horas (MURPHY; MARTINUK, 1991). Doses de 350-500 UI de eCG são comumente usadas em ovelhas depois do pré tratamento com progestágenos para sincronizar e diminuir o intervalo estro-ovulação (CLINE et al., 2001). De acordo com Marques, Campos Filho e Baruseli (2003), o uso isolado de eCG produz uma resposta menos eficiente quando comparado ao hormônio combinado à progestágenos exógenos, sendo que quando utilizados conjuntamente, o eCG pode compensar efeitos deletérios do período de exposição ao progestágeno recrutando novos folículos (NOEL et al., 1994).

Na ovelha, o eCG incrementa a taxa de ovulação pelo recrutamento dos folículos antrais pequenos, eleva sua taxa de crescimento e altera a relação dos diferentes tamanhos foliculares no estro (DRIANCOURT; FRY, 1992). Entretanto, não diminui os efeitos de atresia folicular (MOOR et al., 1985). 
Segundo Vilarinõ et al., (2010), o uso de eCG no momento da retirada do dispositivo, sincroniza o início do cio e o momento da ovulação em 36 e 60 horas respectivamente. De acordo com o estudo, o eCG utilizado no protocolo de curta duração avança o início do estro em até 10 horas e também ocorre uma diminuição no tempo para que aconteça a ovulação.

De acordo com Cox et al., (2012), ovelhas tratadas com eCG mostram menor intervalo ao estro e tendem a apresentar maior maturidade de CL, devido o aumento da produção de estradiol que ocorre nos folículos após o tratamento.

\subsection{Ultrassonografia reprodutiva em ovelhas}

A imagem ultrassonográfica é o produto da reflexão e dispersão dos pulsos ultrassonográficos de alta frequência pelas interfaces de tecidos acústicos. Quando os pulsos refletidos alcançam o transdutor, são convertidos em impulsos elétricos. Esses são transmitidos ao processador do computador para gerar as imagens que variam de preto absoluto ao branco absoluto dependendo das diferentes densidades de cada tecido (LIU et al., 2007).

O diagnóstico de prenhez pela ultrassonografia é fundamental para aprimorar o manejo reprodutivo e intensificar a produtividade na espécie ovina. É um método não invasivo, de elevada precisão e que tem sido normalmente realizado pelas vias abdominal e transretal (CHALHOUB, 2004; PADILLA-RIVAS et al., 2005).

Garcia et al. (1993) utilizando um transdutor de $5 \mathrm{MHz}$ por via transretal, encontraram uma acurácia de $52 \%$ em gestações de 30 dias e $85 \%$ em ovelhas com 32 dias de gestação. Dias et al. (2009), aos 35 dias de gestação, obtiveram acurácia de 98,1\% em ovelhas com prenhez de um único feto e 71,5\% em ovelhas que gestavam dois fetos.

Antes do $35^{\circ}$ dia de gestação, o exame trasretal é o mais indicado. Entre os dias 35 e 70 de prenhez, ambos são equivalentes e a partir da segunda metade da gestação, a via abdominal é a preferida, já que se pode visibilizar uma grande porção do útero gestante (AISEN, 2008). Segundo Kahn (1994), o diagnóstico não deve ser realizado antes do $30^{\circ}$ dia após a cobertura principalmente em rebanhos comerciais.

Na realização do ultrassom transretal, com o animal em posição de estação, esvazia-se o reto para reduzir a possibilidade de fezes envolverem o transdutor, dificultando assim, o contato deste com a parede do reto levando a obtenção de uma imagem de má qualidade (FREITAS; SIMPLÍCIO, 1999). Um suporte de plástico é colocado no transdutor para facilitar a colocação deste no reto, e faz-se a 
lubrificação do transdutor e da cavidade retal utilizando um gel de carboximetilcelulose (DIAS, et al., 2009). Já no exame abdominal, o animal deve permanecer em posição de estação e o transdutor é colocado contra a pele, na região inguinal cruzando o abdômen cranialmente, ligeiramente ao lado do úbere. O método permite uma boa acurácia a partir do $50^{\circ}$ dia de cobertura ou inseminação (FREITAS; SIMPLÍCIO, 1999).

Entre o $15^{\circ}$ e $19^{\circ}$ dias de gestação é observado a presença de líquido intrauterino. A vesícula embrionária é observada entre os dias 16 e 22 de gestação; o embrião entre os dias 18 e 26 e até o $29^{\circ}$ dia são observados os placentomas e batimentos cardíacos. Entre os dias 24 e 32 é observada a membrana aminiótica, e a partir do $30^{\circ}$ dia de gestação observa-se a diferenciação do feto entre cabeça e tronco, movimentos fetais e cordão umbilical (MORAES, 2007). O comprimento crânio-caudal varia entre 4 e $5 \mathrm{~cm}$ no $40^{\circ}$ dia, aumentando para 7 a $8 \mathrm{~cm}$ no $50^{\circ}$ dia. Durante o segundo e o terceiro trimestre da prenhez, numerosos órgãos dos fetos ovinos podem ser detectados. A cavidade cranial, as órbitas, o coração, o estômago e os rins podem ser reconhecidos com clareza (AISEN, 2008).

A imagem no exame de ultrassom por via transretal realizado entre o $20^{\circ}$ e o $30^{\circ}$ dia de gestação será o útero com uma série de vesículas e líquido embrionário imediatamente em posição cranial ou crânio-ventral à bexiga. Já no exame realizado aos 60 dias de gestação, será observado adicionalmente, um feto de aproximadamente $10 \mathrm{~cm}$ de comprimento crânio-caudal (AISEN, 2008).

\subsection{Fatores que interferem na taxa de gestação}

A regulação da secreção e biodisponibilidade das gonadotrofinas depende de uma interação complexa entre vários fatores internos e externos. Os fatores internos em questão incluem ácidos produzidos localmente, aminoácidos e peptídeos, esteróides e hormônios ovarianos foliculares, como a inibina, ativina e folistatina, neurotransmissores e neromoduladores e produtos uterinos. Os fatores externos, incluindo os sinais de fotoperíodo, ferormônios masculinos, nutrição e estresse, também são conhecidos por afetar a função do eixo hipotálamo-hipófise-gonadal. (BARTLEWSKI; BABY; GIFFIN, 2011).

Função lútea inadequada transitória é uma das principais causas da infertilidade que ocorre naturalmente em ruminantes na puberdade, no período pós-parto precoce e durante a transição do anestro sazonal para a época de reprodução (CHRISTENSEN; HARESIGN; KHALID, 2012). Para o reinício da atividade estral pós-parto de ovelhas, são necessários mecanismos que favoreçam a ocorrência da involução uterina, a secreção adequada de 
gonadotrofinas e a diminuição dos efeitos negativos relacionados à amamentação (ARAÚJO, 2006).

$\mathrm{Na}$ fêmea ovina as populações foliculares são muito sensíveis à entrada de nutrientes, podendo ser comprometidas com a restrição nutricional crônica (prolongada) ou aguda (curta duração), que reduzem a taxa de crescimento, o diâmetro máximo e persistência do folículo dominante, interferindo também no tamanho do corpo lúteo, podendo levar o animal ao quadro de anestro (MURPHY et al., 1991).

A obtenção de altos índices reprodutivos em ovinos, segundo OWEN (1988), está na dependência de vários fatores entre os quais citam-se a precocidade, longevidade reprodutiva, frequiência de parições, prolificidade e taxa de sobrevivência de cordeiros. 


\section{OBJETIVO}

Os objetivos do presente estudo foram:

- Comparar a eficiência de protocolos de 9 versus 12 dias quanto a taxa de concepção, gestação e manifestação de estro.

- Avaliar a eficiência do DPR de primeiro e segundo uso através da taxa de concepção, gestação e manifestação de estro.

- Comparar a eficiência do dispositivo DPR versus um dispositivo reconhecido no mercado (Progespon®) através da taxa de concepção, gestação e manifestação de estro comparando o dispositivo feito em esponja e impregnado com medroxiprogesterona versus um dispositivo feito em silicone impregnado com progesterona. 


\section{MATERIAL E MÉTODOS}

O material e métodos abordarão os temas relacionados ao manejo e execução deste trabalho assim como as metodologias empregadas para a elaboração das análises estatísticas.

\subsection{Animais e instalações experimentais}

O experimento foi realizado nas instalações da Cabanha CR situada no município de

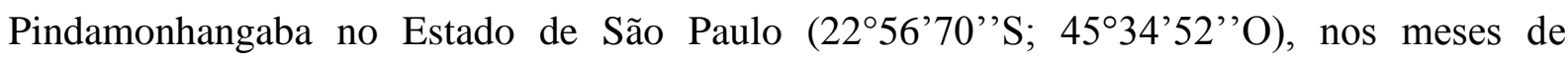
Setembro a Novembro de 2012, período de contraestação reprodutiva. A precipitação pluviométrica média anual na cidade é de $1000 \mathrm{~mm}$ com chuvas bem distribuídas durante o ano e temperaturas médias anuais de $17^{\circ} \mathrm{C}$ a $20^{\circ} \mathrm{C}$.

Foram utilizadas 312 ovelhas da raça Texel, saudáveis, entre 1 e 6 anos de idade, com escore variando de 2 a 4 (scale of 1 to 5) (Menchaca et al., 2009) (Figura 3). Os animais permaneceram em suas instalações habituais da Cabanha, em regime de pastagem formada por Giggs, sal mineral e água à vontade.

Antes do início do experimento foram realizados exames de ultrassonografia para certificar ausência de prenhez nas ovelhas. Foram também realizados exames andrológicos para avaliação seminal dos reprodutores para assegurar a fertilidade dos machos. 
Figura 3 - Seleção dos animais para o projeto

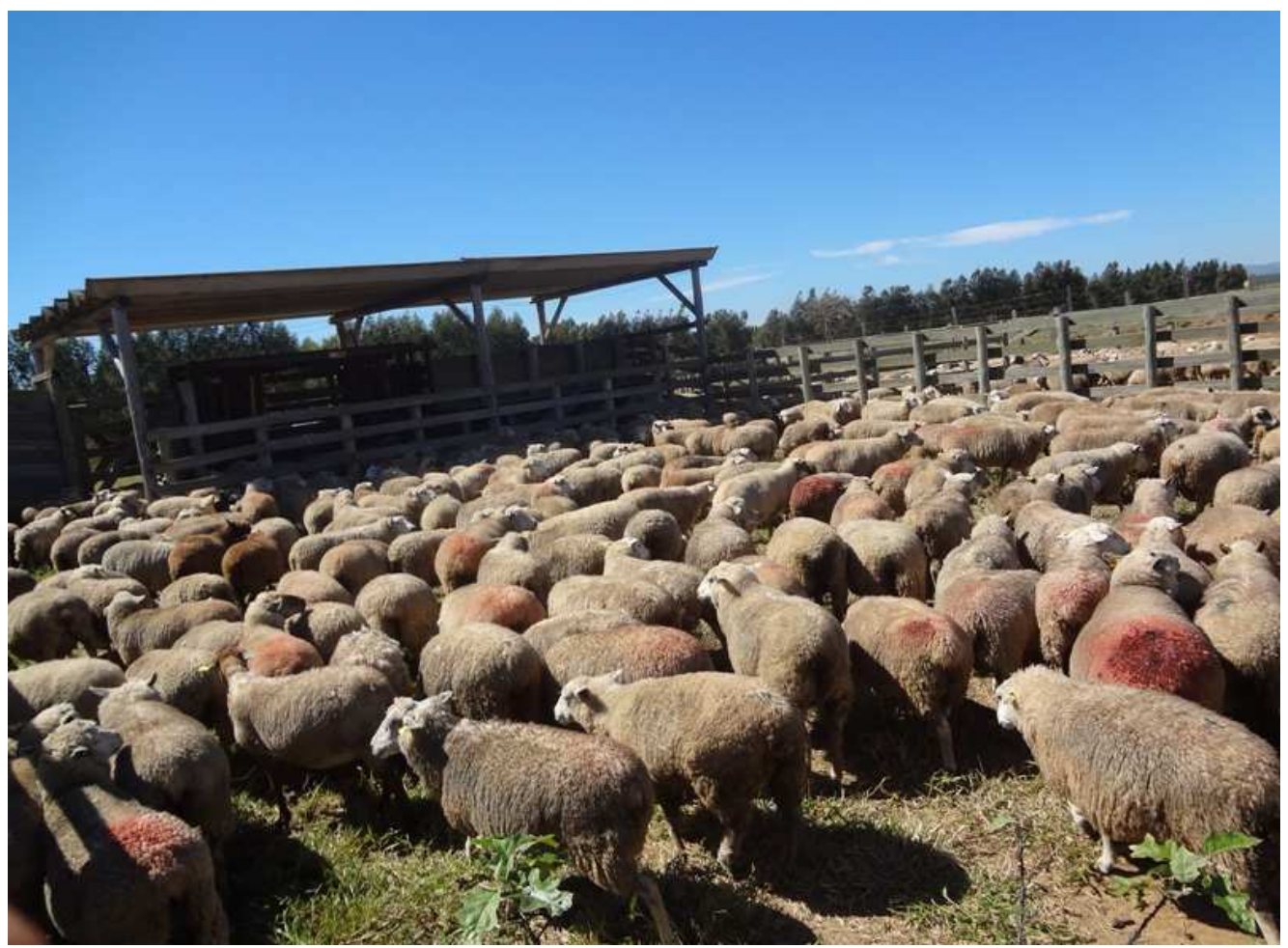

Fonte: (ROCHA, M. S., 2012)

\subsection{Tratamentos}

O projeto foi dividido em dois experimentos consecutivos para sua melhor condução. Considerando os animais que concluíram o tratamento, no experimento 1 foram utilizadas 160 ovelhas e no experimento 2 foram utilizadas 152 ovelhas sem a ocorrência de sincronização prévia. Os animais foram alocados nos grupos de forma aleatória.

\subsubsection{Experimento 1}

No experimento 1, os animais receberam tratamento hormonal por 9 e 12 dias utilizando um dispositivo feito em silicone impregnado com $0,36 \mathrm{~g}$ de progesterona Dispositivo Pequenos Ruminantes (DPR - Tecnopec, Brasil) novo e usado, dessa forma, os animais foram 
subdivididos aleatoriamente, em quatro grupos: protocolo 9 dias com dispositivo novo (G9N, $\mathrm{n}=91$ ), protocolo 9 dias com dispositivo usado ( $\mathrm{G} 9 \mathrm{U}, \mathrm{n}=25)$, protocolo 12 dias com dispositivo novo (G12N, n=26) e protocolo 12 dias com dispositivo usado (G12U, n=18).

No protocolo hormonal de 9 dias, introduziu-se o dispositivo de progesterona $0,36 \mathrm{~g}$ Dispositivo Pequenos Ruminantes (DPR - Tecnopec, Brasil) com o auxílio de gel lubrificante no dia denominado como dia zero D0 no período da manhã. O dispositivo permaneceu por nove dias, no D9 do tratamento fez-se a retirada do dispositivo e imediata aplicação intramuscular de 0,125 mg de cloprostenol (Estron, Agener, Brasil) e $500 \mathrm{UI}$ de eCG (Folligon ${ }^{\circledR}$, Intervet, Netherland).

No protocolo de 12 dias, o dispositivo DPR foi colocado no D0 no período da manhã e permaneceu por 12 dias. Foi então retirado no D12 do protocolo com a imediata aplicação de 0,125 mg de cloprostenol (Estron, Agener, Brasil) e 500 UI de eCG (Folligon, Intervet, Holanda).

Ocorreram problemas relacionados a utilização do dispositivo DPR, como a dificuldade no momento da retirada do dispositivo que se partiu em alguns casos e em outras situações a corda que segura o dispositivo se rompeu.

O dispositivo usado havia sido utilizado em protocolo anterior com duração de 9 dias e após a sua retirada foi feita a lavagem manual do dispositivo e posterior imersão em solução sanitizante adequada. Em sequência, o dispositivo foi seco e guardado em local fresco e arejado até a sua próxima utilização.

\subsubsection{Experimento 2}

No experimento 2, as ovelhas receberam protocolo hormonal por 9 dias utilizando o dispositivo feito em esponja e impregnado com medroxiprogesterona 0,60 mg Progespon ${ }^{\circledR}$ (MSD, Brasil), e o dispositivo feito em silicone impregnado com progesterona 0,36 $\mathrm{g}$ Dispositivo Pequenos Ruminantes (DPR - Tecnopec, Brasil). Dessa forma, os animais foram subdivididos em dois grupos: protocolo de 9 dias utilizando a esponja Progespon ${ }^{\circledR}$ (MSD, Brasil) (GP, n=61) e protocolo de 9 dias utilizando o Dispositivo Pequenos Ruminantes (DPR - Tecnopec, Brasil) (GDX, n=91). O protocolo utilizado foi semelhante ao experimento 1 do G9N, exceto pelo tipo de dispositivo utilizado sendo DPR no GDPR e o Progespon® no GP. 
4.3 Manejo de Monta e Observação de estro

Todas as ovelhas permaneceram juntas em um piquete de $170 \mathrm{~m}^{2}$ durante o dia, no final da tarde eram recolhidas em um galpão para proteção contra predadores e na manhã seguinte retornavam novamente ao mesmo piquete. Foram colocadas em monta natural na proporção de 1 reprodutor de conhecida fertilidade para cada 10 ovelhas, por um período de 72 horas com início no D9 para os grupos G9N e G9U e no D12 para os grupos G12N e G12U.

Durante o período de monta natural, nos dois experimentos, os reprodutores tiveram a região peitoral próxima ao esterno pintada diariamente com tinta colorida trocando de cor a cada 24 horas para verificar o período da cobertura (Figura 4). Com isto, as ovelhas que tiveram a região posterior marcada com tinta foram consideradas em estro e fertilizadas pelos machos (Figura 5).

Cerca de 30 dias antes da estação de monta, os animais passaram por tosquia da lã, procedimento realizado anualmente na cabanha.

Figura 4 - Aplicação da mistura de tinta em pó e óleo na região do esterno do reprodutor

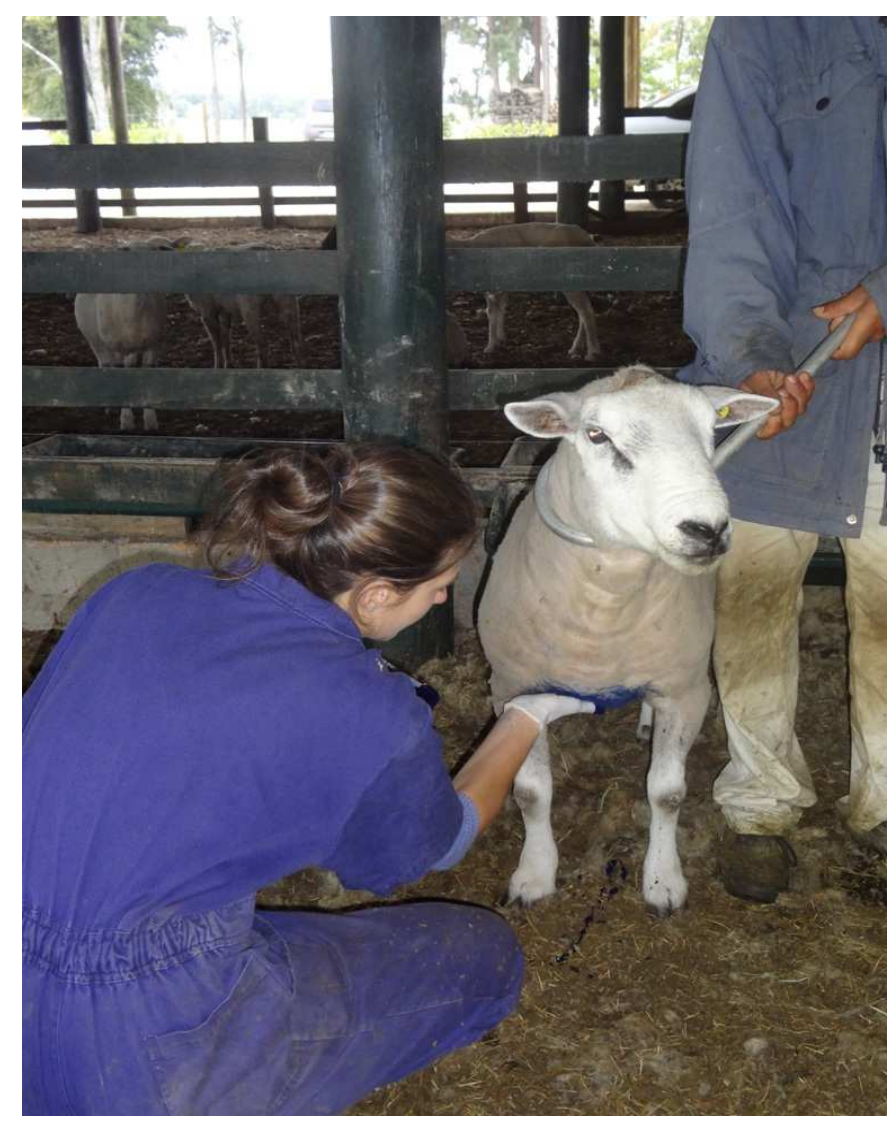

Fonte: ROCHA, M. S. (2012) 
Figura 5 - Ovelhas marcadas após a monta

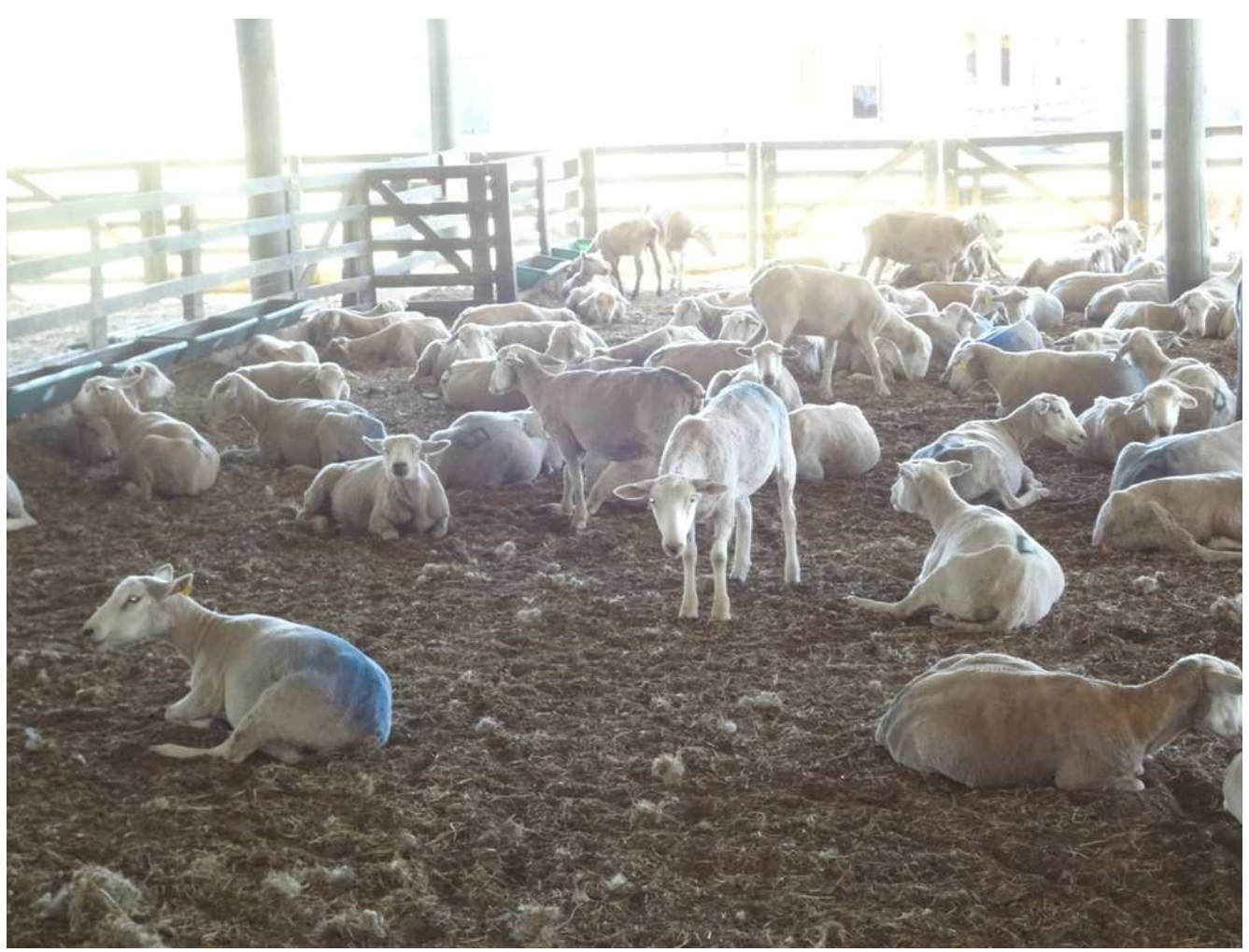

Fonte: (ROCHA, M. S., 2012).

4.4 Exames ultrassonográficos para detecção de prenhez

Os exames ultrassonográficos para detecção de prenhez foram realizados 30 e 60 dias após o término do período de cobertura. Para a realização do exame foi utilizado o equipamento Chison 9300VET, (Chison, KYLUMAX, Brasil) com transdutor linear de 5.0 MHz por via transretal nos exames de 30 dias pós-tratamento e o equipamento Chisson D600 (Chison, KYLUMAX, Brasil) com transdutor microconvexo de 5.0 MHz por via abdominal nos exames realizados 60 dias após o tratamento.

Durante o exame as ovelhas foram contidas em posição de estação com o auxílio de um funcionário da cabanha.

No momento do exame por via transretal, o transdutor foi inserido no reto dos animais com o auxílio de gel lubrificante, e feito a varredura do útero buscando imagens compatíveis com uma gestação de 30 dias em ovinos. 
No exame realizado por via abdominal, o transdutor foi colocado na região perimamária abdominal, porção caudal da cavidade abdominal que é naturalmente deslanada, com auxílio de gel lubrificante para facilitar a captura da imagem.

Foi considerada com prenhez positiva, a ovelha que apresentava placentomas e líquido uterino mesmo sem a visualização do feto nos exames realizados aos 30 dias e aos 60 dias.

Os animais que foram diagnosticados com prenhez positiva no exame de 30 dias e posteriormente se apresentaram com diagnóstico negativo para prenhez foram computados no resultado final como prenhez negativa.

4.5 Colheitas de sangue para dosagem de progesterona

As colheitas de sangue foram realizadas sempre no período da manhã, entre 8:00 e 10:00 horas, por punção da veia jugular externa por meio de agulha e tubo a vácuo, sem anticoagulante, do sistema Vacutainer (BD®), 10 dias após a retirada dos dispositivos. Foram colhidas amostras de 64 animais no Experimento 1 e 76 ovelhas no Experimento 2, com a finalidade de avaliar a presença de ovulação após o tratamento hormonal. O sangue coletado era reservado em isopor com gelo até o final das colheitas e centrifugado a $1500 \mathrm{G}$ por 20 minutos. Em seguida o soro era retirado com auxílio de pipeta e ponteira individual e colocado em tubo Eppendorf® identificado e armazenado em freezer a $-20^{\circ} \mathrm{C}$.

4.6 Análise da progesterona por radioimunoensaio (RIE)

Para dosagem de progesterona sérica, utilizou-se a técnica de radioimunoensaio (RIE) em fase sólida por meio de conjunto comercial Immunotech ${ }^{\circledR}$ (France), desenvolvido para avaliação quantitativa de progesterona no soro humano, e validado previamente para uso em soro de ovinos (KAYA et al., 2013). Os ensaios hormonais foram realizados de acordo com o protocolo fornecido pelo fabricante.

Todos os parâmetros de controle de qualidade dos ensaios hormonais foram analisados conforme rotina empregada no Laboratório de Dosagens Hormonais. Foram calculados os Coeficientes de Variação (CV) intra-ensaio, utilizando-se valores altos e baixos, no início e final de cada ensaio. Foi também calculada a porcentagem de ligação B/BO, a sensibilidade 
do ensaio para P4 foi de $0,01 \mathrm{ng} / \mathrm{ml}$, e o coeficiente de variação intra-ensaio e inter-ensaio foram de $6,5 \%$ e $7,2 \%$ respectivamente.

4.7 Metodologia das análises

Como metodologias das análises foi considerado taxa de manifestação do estro: total de fêmeas marcadas com tinta sobre o total de ovelhas no experimento, taxa de concepção: total de ovelhas prenhes sobre o total de ovelhas marcadas com tinta, taxa de prenhez: total de ovelhas prenhes sobre o total de ovelhas no experimento e dispersão no intervalo de cio: o período em que as ovelhas foram marcadas com tinta durante as 72 horas de cobertura.

\subsection{Análise estatística}

Os dados obtidos foram analisados através do programa SAS System for Windows (SAS, 2000). A variável intervalo cio/cobertura (dispersão no intervalo de cio) foi avaliada quanto à normalidade dos resíduos (distribuição normal) e homogeneidade das variâncias. Caso não obedecesse a estas premissas, foi transformado (logaritmo na base $10-\log _{10} X$; Raiz quadrada - RQ X; Quadrado - $X^{2}$ ) e se a normalidade não fosse obtida, empregava-se, então, o procedimento NPAR1WAY de análise de variância não paramétrica. Na avaliação do efeito dos tratamentos foram utilizados os testes LSD (Least Significant Difference; comparações múltiplas) e t de Student para variáveis paramétricas e o teste de Wilcoxon para variáveis não paramétricas. $\mathrm{Na}$ análise do efeito dos tratamentos sobre a variabilidade do intervalo cio/cobertura, foi utilizado o teste de Levene. Para descrição dos resultados, foram empregadas as médias e seus respectivos erros padrões (média \pm erro padrão da média) dos dados originais. Para a avaliação das variáveis dicotômicas foram utilizados os testes de Chi quadrado (com a correção de Yates) ou Exato de Fisher quando apropriado. O nível de significância utilizado para rejeitar H0 (hipótese de nulidade) foi de 5\%, isto é, para um nível 
de significância menor que 0,05 , considerou-se que ocorreram diferenças estatísticas entre os tratamentos com progesterona. 
5.1 Resultados do experimento 1

No experimento 1, não houve diferença entre os grupos tratados com protocolo de 9 dias comparado com o de 12 dias quanto a taxa de manifestação de estro (G9N: 84,61\% vs G12N: 84,61\%; p=1 e G9U: 64,0\% vs G12U: 55,5\%; p=0,80), taxa de concepção (G9N: 45,4\% vs G12N: 35,06\%; p=0,52 e G9U: 60,0\% vs G12U: 50,0\%; p=0,92) e taxa de prenhez (G9N: $38,46 \%$ vs G12N: 29,67\%; p=0,54 e G9U: 33,3\% vs G12U: 32,0\%; p=0,92) (Tabela 1).

Tabela 1 - Taxas de manifestação de estro, concepção e prenhez de ovelhas submetidas a protocolo de indução do estro com uso do Dispositivo Pequenos Ruminantes (DPR Tecnopec, Brasil) utilizado por 9 dias novo e usado e 12 dias novo e usado

\begin{tabular}{l|c|c|c|c} 
Dispositivo & Protocolo & $\begin{array}{c}\text { Manifestação } \\
\text { de estro }\end{array}$ & Prenhez & Concepção \\
\hline \multirow{2}{*}{ Novo } & 9 dias & $84,61 \% *$ & $38,46 \%$ & $45,4 \%$ \\
& 12 dias & $84,61 \% *$ & $29,67 \%$ & $35,06 \%$ \\
Usado & 9 dias & $64,0 \%$ & $33,3 \%$ & $60,0 \%$ \\
& 12 dias & $55,5 \%$ & $32,00 \%$ & $50,0 \%$ \\
\hline
\end{tabular}

Foi observado um melhor desempenho do dispositivo novo em comparação com o usado na taxa de manifestação de estro (G9N: 84,61\% vs G9U: 64,0\%; p=0,04 e G12N: 84,61\% vs G12U: 55,55\%; p=0,07), contudo, em relação a taxa de prenhez (G9N: 38,46\% vs G9U: 33,3\%; p=0,71 e G12N: 29,67\% vs G12U: 32,0\%; p=0,97) e concepção (G9N: 45,45\% vs G12U: 50\%; p= 0,52 e G9U: 60\% vs G12N: 35,06\%; $\mathrm{p}=0,92$ ) não foi observado diferença entre eles (Tabela 1). 
Observou-se também, a ocorrência de menor dispersão no intervalo de cio, ou seja, uma tendência a maior concentração do período da manifestação do estro no protocolo de 9 dias quando comparado ao de 12 (G9N: 46,54\% vs G12N: 78,88\%; p=0,07 e G9U: 51,12\% vs G12U: 81,11\%; p=0,004) ao longo das 72 horas de monta natural, não observando essa diferença quando utilizado o dispositivo novo comparado com o usado (G9N:46,54\% vs G9U: 51,12\%; p=0,61 e G12N: 78,88\% vs G12U: 81,11\%; p=0,73) (Tabela 1).

Tabela 2 - Dispersão de cio em relação aos protocolos de 9 versus 12 dias, DPR novo versus usado e DPR versus Progespon®

\begin{tabular}{l|c|c|c|c|c}
\hline & Progespon ${ }^{\circledR}$ & DPR Novo & DPR Novo & DPR Usado & DPR Usado \\
\hline $\begin{array}{l}\text { Dias de } \\
\text { protocolo }\end{array}$ & 9 dias & 12 dias & 9 dias & 12 dias \\
Dispersão & 56,61 & 46,54 & 78,88 & $51,12^{*}$ & 81,11 \\
de cio $(\%)$ & & & & \\
\hline
\end{tabular}


5.2 Resultados do experimento 2

No experimento 2, não houve diferença entre o grupo tratado com o Dispositivo Pequenos Ruminantes (DPR - Tecnopec, Brasil) comparado com o Progespon ${ }^{\circledR}$ (MSD, Brasil) em relação a taxa de manifestação de estro (GP: 81,96\% vs GDX: 84,61\%; p=0,13), taxa de concepção (GP: 32,0\% vs 35,06\%; p=0,86), taxa de prenhez (GP: 26,22\% vs GDX: 29,67\%; p=0,78) e concentração do período da manifestação do estro (GP: 56,61\% vs GDX: 46,54\%; $\mathrm{p}=0,37$ ) (Tabela 3).

Tabela 3 - Taxas de manifestação de estro, concepção e prenhez de ovelhas submetidas a protocolo de indução do estro de 9 dias utilizando Progespon ${ }^{\circledR}$ (MSD, Brasil) versus Dispositivo Pequenos Ruminantes (DPR - Tecnopec, Brasil)

\begin{tabular}{c|c|c|c|c} 
Dispositivo & Protocolo & $\begin{array}{c}\text { Manifestação } \\
\text { de estro }\end{array}$ & Prenhez & Concepção \\
\hline DPR & 9 dias & $84,61 \%$ & $29,67 \%$ & $35,0 \%$ \\
Progespon & 9 dias & $81,96 \%$ & $26,2 \%$ & $32,0 \%$ \\
\hline
\end{tabular}


5.3 Resultados da dosagem hormonal

No experimento 1 e 2, os animais avaliados apresentaram valores de progesterona sérica acima de 1,3 ng/ml e 1,9 ng/ml, respectivamente, caracterizando a ocorrência de ovulação em todos os animais avaliados. 


\section{DISCUSSÃO}

As hipóteses deste trabalho foram aceitas em relação à eficácia semelhante entre os protocolos de 9 versus 12 dias e DPR versus Progespon® em relação a taxa de manifestação de estro, concepção e prenhez. Porém, não foi aceita em relação ao dispositivo novo que obteve melhores resultados na manifestação de estro comparado ao usado e também em relação ao protocolo de 9 dias que foi capaz de causar menor dispersão do estro em comparação ao de 12 dias, discutidos a seguir.

Com base nos resultados obtidos foi possível observar que no experimento 1 não houve diferença entre os grupos tratados com protocolo de 9 dias comparado com o de 12 dias utilizando dispositivo novo ou usado quanto a taxa de manifestação de estro, concepção e prenhez. Resultados muito semelhantes foram observados por Castilho et al. (2013) que não encontraram diferenças entre grupos tratados com protocolos de 9 e 14 dias respectivamente, quanto a manifestação de estro $(69,6 \%$ e $80 \%)$, prenhez $(34,8 \%$ e $44 \%)$ e concepção (50\% e 55\%). Dogan e Nur (2006) e Santos et al. (2011), também utilizando ovelhas lanadas na contraestação obtiveram taxas de gestação de $36 \%$ e 41,2\% respectivamente. Esses resultados nos mostram que a redução no período de exposição ao progestágeno utilizando protocolos de menor duração se mostra uma alternativa viável, podendo facilitar o manejo reprodutivo e com a possibilidade de reutilizar o implante de progesterona reduzindo o custo do tratamento. Segundo Vinoles et al. (2001), a utilização de protocolos de curta duração ainda teria a vantagem de causar ovulações com folículos mais jovens, atribuindo a isso bons resultados das taxas de fertilidade ( $87 \%$ de prenhez) em comparação aos longos (63\% de prenhez).

Santos et al. (2011), comparando protocolo hormonal entre ovelhas lanadas e deslanadas obtiveram taxas de apresentação de estro e de prenhez respectivamente de 84,0 e 36,0\% resultantes da sincronização em ovelhas lanadas e de 87,0 e 56,6\% em ovelhas deslanadas. De acordo com Sasa et al. (2002), a diferença nas respostas reprodutivas entre ovelhas lanadas e deslanas pode ser explicado pela ocorrência de ovulação silenciosa, visto que as ovelhas lanadas têm suas atividades reprodutivas interrompidas no período de Agosto a Novembro, ao contrário das ovelhas deslanadas que não apresentam estacionalidade reprodutiva. Esse fenômeno é comumente observado em ovelhas adultas no início da estação reprodutiva e ocorre devido uma falha na secreção de estradiol que necessita de uma prévia exposição à progesterona para que aconteçam os sinais de estro, ou seja, evento associado com a 
luteinização insuficiente do CL (HUNTER, 1991). Segundo Bartlewski, Baby e Giffin (2011), é provável que existam diferenças entre as raças de ovinos, com diferentes taxas de ovulação em termos de tamanho dos folículos que adquirem a capacidade de responder a estímulos hormonais.

O resultado da associação de eCG com progestágenos se mostra mais eficiente quando comparado a outros tratamentos hormonais. Oliveira-Muzante et al. (2011), comparando um protocolo hormonal a base de duas aplicações de prostaglandina com intervalo de 7 dias (Synchrovine ${ }^{\circledR}$ ) com um protocolo de 13 dias que associou implante de progesterona com eCG, obteve resultado de fertilidade de $26 \%$ e $48 \%$ respectivamente. Isso se deve a ação do eCG de estimular o crescimento e maturação folicular semelhante ao FSH que incrementa a taxa de ovulação pelo recrutamento dos folículos antrais pequenos, elevando sua taxa de crescimento e alterando a relação dos diferentes tamanhos foliculares no estro (DRIANCOURT; FRY, 1992).

De acordo com os resultados, foi observado um melhor desempenho do dispositivo novo em comparação com o usado na taxa de manifestação de estro. Esse fato pode ser explicado devido à alta concentração de progesterona no dispositivo novo comparado ao usado. De acordo com Dias et al., (2012), no dispositivo novo, a concentração liberada de progesterona é semelhante à encontrada na situação fisiológica de atividade estral, apresentando no D9 após a colocação do dispositivo 7,33 ng/ml de progesterona respectivamente. Já no caso do dispositivo usado, a concentração encontrada é de 2,5ng/ml, podendo não ser suficiente para sensibilizar o hipotálamo de ovelhas em anestro. Porém, pelo fato de não ter sido observado diferenças nas taxas de prenhez e concepção, pode-se discutir se o uso do dispositivo usado pode não ser aconselhável na monta natural devido à falha na demonstração de cio, mas pode não interferir em resultados de inseminação artificial em tempo fixo, que não tem a necessidade de manifestação dos sinais de estro. Resultados estes que não corroboram com Vilariño, Rubianes e Menchaca (2011), que observaram capacidade semelhante entre o dispositivo DICO® novo e usado em manifestar o cio em ovelhas. Assim como Cox et al. (2012) que também observaram manifestação de cio semelhante entre grupos de dispositivos novos e usados.

De acordo com os resultados da dosagem de progesterona sérica, todos os animais apresentaram valores acima de $1 \mathrm{ng} / \mathrm{ml}$, caracterizando ovulação e eficácia dos protocolos hormonais utilizados em induzir o estro, mesmo que a maior taxa de prenhez observada tenha sido de 38,46\% no protocolo de 9 dias com dispositivo novo. Vilarino, Rubianes e Menchaca (2011), sugeriram que a taxa de prenhez em seu experimento tenha sido prejudicada pela 
ovulação de folículos mais velhos provenientes da utilização dos dispositivos de segundo e terceiro uso, devido a concentração mais baixa de progesterona nestes grupos. Segundo Bartlewski, Baby e Giffin (2011), a taxa de gestação pode ser influenciada por fatores relacionados a estresse e nutrição.

Observou-se também, a ocorrência de menor dispersão no intervalo de cio, ou seja, uma maior concentração do período da manifestação do estro no protocolo de 9 dias quando comparado ao de 12 ao longo das 72 horas de monta natural, não observando essa diferença quando utilizado o dispositivo novo comparado com o usado. Esse fato também foi observado por Bicudo e Sousa (2002) que obtiveram uma menor dispersão no intervalo de cio para o protocolo de curta duração (6 dias) em comparação ao protocolo longo (14 dias). Diante dos resultados, pode-se inferir que a utilização de protocolos hormonais curtos são mais aconselháveis para a realização da inseminação artificial por concentrarem melhor a ocorrência de estro, provavelmente por causa de uma melhor sincronização da ovulação.

No experimento 2, não houve diferença entre o grupo tratado com o Dispositivo Pequenos Ruminantes (DPR - Tecnopec, Brasil) comparado com o Progespon ${ }^{\circledR}$ (MSD, Brasil) em relação as taxas de manifestação de estro, concepção e prenhez e concentração do período de manifestação do estro. Portanto, ambos dispositivos apresentaram eficácia semelhante na indução e sincronização de cio. Resultado também encontrado por Vilariño, Rubianes e Menchaca (2010), que comprovaram eficácia semelhante entre dois tipos diferentes de dispositivos intravaginais, DICO® e o CIDR-G® utilizados por 14 dias. 


\section{CONCLUSÃO}

Diante dos resultados, infere-se que o protocolo de 9 e 12 dias tem resultados semelhantes na taxa de demonstração de estro, prenhez e concepção em ovelhas da raça Texel submetidas ao protocolo hormonal na contra-estação reprodutiva, que o uso do dispositivo (DPR - Tecnopec) novo se mostrou mais efetivo na taxa de manifestação de estro quando comparado ao dispositivo (DPR - Tecnopec) usado e que o protocolo de 9 dias resultou em menor dispersão do estro se comparado com o de 12 dias. Conclui-se também que ambos dispositivos (DPR - Tecnopec e Progespon ${ }^{\circledR}$ - MSD), são semelhantes quanto à eficácia de indução do estro e na taxa de prenhez em ovelhas Texel durante a contra-estação reprodutiva. 


\section{REFERÊNCIAS}

ABECIA, J. A.; FORCADA, F.; GONZÁLEZ-BULNES, A. Hormonal control of reproduction in small ruminants. Animal Reproduction Science, v. 30, n 3-4, 2012.

AISEN, E. G. Reprodução ovina e caprina. In: SOTO, A. T.; GÓMEZ, M. V.; SOTA, R. L. Fecundação, gestação e parto. Diagnóstico da gestação. São Paulo: MedVet, 2008. p. 115132.

AMIRIDIS, G. S.; CSEH, S. Assisted reproductive technologies in the reproductive management of small ruminants. Animal Reproduction Science, v. 130, p. 152- 161, 2012.

ANUALPEC. Anuário da Pecuária Brasileira. São Paulo, 2012, p. 306.

ARAÚJO, R. C. Produção de leite e atividade ovariana pós-parto de ovelhas Santa Inês alimentadas com casca de soja em substituição ao feno "coastcross" (Cynodon sp). 2006. 136f. Dissertação (Mestrado em Ciência Animal e Pastagens) - Programa de Pós-graduação em Agronomia, Escola Superior de Agricultura Luiz de Queiroz, Piracicaba, 2006.

ASPACO - Associação Paulista de criadores de Ovinos. Disponível em: $<$ http://www.aspaco.com.br/raças/texel>. Acesso em: 01 set. 2013.

BARRET, D. M. W.; BARTLEWSKI, P. M.; BATISTA-ARTEAGA, M.; SYMINGTON, A.; RAWLINGS, N. C. Ultrasound and endocrine evaluation of the ovarian response to a single dose of 500UI of eCG following a 12-day treatment with progestogen realising intravaginal sponges in the breeding and nonbreeding seasons in ewe. Theriogenology, v. 61, p. 311-327, 2004.

BARTLEWSKI, P. M.; BABY, T. E.; GIFFIN, J. L. Reproductive cycles in sheep. Animal Reproduction Science, v. 124, p. 259-268, 2011.

BEZERRA, J. A. Revolução Sertaneja. Revista Globo Rural, São Paulo, ano 20, n. 28, p. 20-26, 2004.

BICUDO, S. D.; SOUSA, D. B. Associação de progestágeno, prostaglandina e eCG em protocolo de curta duração para indução/sincronização do estro em ovelhas. In: MOSTRA CIENTÍFICA DA FACULDADE DE MEDICINA VETERINÁRIA E ZOOTECNIA DA UNESP, 6., 2002, Botucatu, SP. Anais... Botucatu: FMVZ-UNESP.,2002. Disponível em: $<$ http://www.fmvz.unesp.br/sony/curtadur.pdf $\geq$. Acesso em: 10 out. 2013.

CAHILL, L. P. Folliculogenesis and ovulation rate in sheep. In: Reproduction in sheep. LINDSAY, D. R.; PEARCE, D. T. Academy of Science Australian Wool Corporation, p. 9298, 1984.

CAMPBELL, B. K.; MANN, G. E.; McNEILLY, A. S.; BAIRD, D. T. The pattern of ovarian inibin, estradiol and androstenedione secretion during the estrous cycle in the ewe.

Endocrinology, v. 127, p. 227-235, 1990. 
CASTILHO, C.; ALMEIDA, M. F.; COSTA, M. Z.; DE CESARE, A. G.; GABRIEL FILHO, L. R. A. Protocolos de indução e sincronização do estro em ovelhas. Ciência Animal Brasileira, v. 14, n. 1, p. 91-97, 2013.

CHALHOUB, M. Aspectos ultra-sonográficos e aspecto hormonal da gestação ovina (Ovis rires) nas raças Bergamácia e Ideal. 2000. 120 f. Tese (Doutorado em Medicina Veterinária) - Universidade Estadual Paulista, São Paulo, 2000.

CHRISTENSEN, A. C. M.; HARESIGN, W.; KHALID, M. Progesterone exposure of the preovulatory follicle in the seasonally anestrous ewe alters the expression of angiogenic growth factors in the early corpus luteum. Theriogenology, v. 77, p. 1648-1660, 2012.

CLINE, M. A.; RALSTON, J. N.; SEALS, C. Intervals from norgestomet withdrawal and injection of equine chorionic gonadotrophin or P.G. 600 to estrus and ovulation in ewes. Journal of Animal Science, v. 79, p. 589-594, 2001.

CONTRERAS-SOLIS.; VASQUEZ, B.; DIAZ, T.; LETELIER, C.; LOPEZ-SEBASTIAN, A.; GONZALES-BULNES, A. Efficiency of estrous synchronization in tropical sheep by combining short-interval cloprostenol-based protocols and 'male effect'. Theriogenology, v. 71, p. 1018-1025, 2009.

COX, J. F.; ALLENDEL, R.; LARA, E.; LEIVA, A.; DÍAZ, T.; DORADO, J.; SARAVIA, F. Follicular dynamics, interval to ovulation and fertility after AI in short-term progesterone and PGF2a oestrous synchronization protocol in sheep. Reproduction in Domestic Animals, v. 47, p. 946-951, 2012.

DIAS, F. E. F.; VILLARROEL, A. B. S.; FREITAS, V. J. F. Sincronização do estro e da ovulação em ovelhas: Uma Revisão. Revista Científica de Produção Animal, v. 2, n. 1, p. 119-129, 2000.

DIAS, L. M. K.; SOUZA, J. C.; ASSIS, R. M.; RAYMUNDO, C. M. Diagnóstico de gestação, quantificação e sexagem fetal por ultra-sonografia em ovelhas. Ciência e Agrotecnologia, v. 33, n. 3, p. 911-916, 2009.

DIAS, L. M. K.; VIAU, P.; NICOLAU, S. S.; SALES, J. N. S.; PAES DE BARROS, M. B.; ALONSO, M. A.; OLIVEIRA, C. A. Avaliação da liberação de progesterona na reutilização de um novo dispositivo intravaginal em ovelhas (dados preliminares). In: REUNIÃO ANUAL DA SOCIEDADE BRASILEIRA DE TECNOLOGIA DE EMBRIÕES, 26., 2012, Foz do Iguaçu. Anais.... Foz do Iguaçu: Animal Reproduction, 2012. v. 9. p. 513.

DIAS, L. M. K.; VIAU, P,; SALES, J. N. S, SANTOS, F. F.; MELLO, D. M. D.; VALENTIM, R.; OLIVEIRA, C. A. Efeito do reúso de um novo dispositivo de progesterona na dinâmica folicular de ovelhas In: REUNIÃO ANUAL DA SOCIEDADE BRASILEIRA DE TECNOLOGIA DE EMBRIÕES, 27., 2013, Praia do Forte. Anais... Praia do Forte: Animal Reproduction, 2013. v. 10. p. 466.

DOGAN, I.; NUR, Z. Different estrous induction methods during the non-breeding season in Kivircik ewes. Veterinary Medicine, v. 51 n. 4, p. 133-138, 2006. 
DOWNING, J. A.; SCARAMUZZI, R. J. Nutrient effects on ovulation rate, ovarian function and the secretion of gonadotrophicand metabolic hormones in sheep. Journal of Reproduction and Fertility, Supplement 43, p. 209-227, 1991.

DRIANCOURT, M. A.; FRY, R. C. Effect of superovulation with pFSH or PMSG on growth and maturation of the ovulatory follicles in sheep. Animal Reproduction Science, v. 27, p. 279-292, 1992.

DRIANCOURT, M. A. Lack of between-follicle interaction in the sheep ovary. Reproduction, Nutrition and Development, v. 34, p. 249-260, 1994.

DRION, P. V.; FURTOOS, V.; BARIL, G. Four years of induction/synchronization of estrus in dairy goats: effect on the evolution of eCG binding rate in relation with the parameters of reproduction. Reproduction, Nutrition and Development, v. 41, p. 401-412, 2001.

EVANS, A. C.; DUFFY, P.; HYNES, N.; BOLAND, M. P. Waves of follicle development during the estrous cycle in sheep. Theriogenology, v. 53, p. 699-715, 2000.

EYERKAUFER, M. L.; COSTA, A.; FARIA, A. C. Métodos de custeio por absorção e variável na ovinocultura de corte: estudo de caso em uma cabanha. Organizações Rurais \& Agroindustriais, v. 9, n. 2, p. 202-215, 2007.

FIERRO, S.; GIL, J.; VINOLES, C.; OLIVEIRA-MUZANTE, J. The use of prostaglandins in controlling estrous cycle of the ewe: A review. Theriogenology, v. 79, p. 399-408, 2013.

FINDLAY, J. K.; DRUMMOND, A. E.; BRITT, K. L.; DYSON, M.; WREFORD, N. G.; ROBERTSON, D. M.; GROOME, N. P.; JONES, M. E.; SIMPSON, E. R. The roles of activins, inhibins and estrogen in early committed follicles. Molecular and Cellular Endocrinology, v. 163, p. 81-87, 2000.

FONSECA, J. F. Estratégias para o controle do ciclo estral e superovulação em ovinos e caprinos. In: CONGRESSO BRASILEIRO DE REPRODUÇÃO ANIMAL, 2005, Goiânia, GO. Anais... 2005, 16.

FREITAS, V. J. F.; SIMPLÍCIO, A. A. Diagnóstico de prenhez em caprinos: uma revisão. Ciência animal, v. 9, n. 2, p. 51-59, 1999.

FURUSHO-GARCIA, I. F.; PEREZ, J. R. O.; BONAGURIO, S.; ASSIS, R. M.; PEDREIRA, B. C.; SOUZA, X. R. Desempenho de Cordeiros Santa Inês Puros e Cruzas Santa Inês com Texel, Ile de France e Bergamácia. Revista Brasileira de Zootecnia, v. 33, n. 6, p. 15911603, 2004.

GARCIA, A.; NEARLY, M. K.; KELLY, G. R.; PIERSON, R. A. Accuracy of ultrasonography in early pregnancy diagnosis in the ewe. Therigenology, v. 39, p. 847-61, 1993.

GARCIA, I. F. F.; PEREZ, J. R. O.; OLIVEIRA, M. V. Características de carcaça de cordeiros Texel x Bergamácia, Texel x Santa Inês e Santa Inês puros, terminados em confinamento, com casca de café como parte da dieta. Revista Brasileira de Zootecnia, v. 29, n. 1, p. 253-260, 2000. 
GASTON-PARRY, O.; HEASMAN, K.; NEMORIN, J. K. E.; ROBINSON, T. J. A radioimmunoassay for fluorgestone acetate (FGA) and its application to the measurement of plasma FGA and progesterone in ewes treated with FGA impregnated intravaginal sponges. Australian Journal of Biological Science, v. 41, p. 57-67, 1988.

GOODMAN, R. L.; BITTMAN, E. L.; FOSTER, D. L.; KARSCH, F. J. The endocrine basis of the synergistic suppression of luteinizing hormone by estradiol and progesterone.

Endocrinology, v. 109, p. 1414-1417, 1981.

GOLDMAN, B. D. The circadian timing systems and reproduction in mammals. Steroids, v. 64, p. 679-685, 1999.

GONZALES-BULNES, A.; VEIGA-LOPES, A.; GARCIA, P.; GARCIA-GARCIA, R. M.; ARIZNAVARRETA, C.; SANCHEZ, M. A. Effects of progestagens and prostaglandin analogues on ovarian function and embryo viability in sheep. Theriogenology, v. 63, p. 2523-2534, 2005.

HAFEZ, B.; HAFEZ, E. S. E. Reprodução animal. Barueri: Manole, 2004. p. 173-192.

HAUGER, R. L.; KARSCH, F. J.; FOSTER, D. L. A new concept for control of the estrous cycle of the ewe based on the temporal relationships between luteinizing hormone, estradiol and progesterone in peripheral serum and evidence that progesterone inhibits tonic LH secretion. Endocrinology, v. 101, n. 3, p. 807-817, 1977.

HERVÉ, V.; ROY, F.; BERTIN, J.; GUILLOU, F.; MAUREL, M. C. Antiequine chorionic gonadotropin (eCG) antibodies generated in goats treated with eCG for the induction of ovulation modulate the luteinizing hormone and follicle-stimulating hormone bioactivities of eCG differently. Endocrinology, v. 145, p. 294-303, 2004.

HUNTER, M. G. Characteristics and causes of the inadequate corpus luteum. Journal of Reproduction and Fertility Supplement, v. 43, p. 91-99, 1991.

KAYA, S.; KAÇAR, C.; KAYA, D.; ASLAN, S. The effectiveness of supplemental administration of progesterone with GnRH, hCG and PGF2 $\alpha$ on the fertility of Tuj sheep during the non-breeding season. Small Ruminant Research, v. 113, p. 365-370, 2013.

LEYVA, V.; BUCKRELL, B. C.; WALTON, J. S. Regulation of follicular activity and ovulation in ewes by exogenous progestagen. Theriogenology, v. 50, p. 395-416, 1998.

LIU, X. D. Q.; HART, E. J.; BARRETT, D. M.; RAWLINGS, N. C.; PIERSON, R. A.; BARTLEWSKI, P. M. Ultrasonographic characteristics of ovulatory follicles and associated endocrine changes in cyclic ewes treated with medroxyprogesterone acetate (MAP) releasing intravaginal sponge and equine chorionic gonadotropin (eCG). Reproduction Domestic Animal, v. 42, n. 1, p. 393-401, 2007.

MALPAUX, B.; MIGAUD, M.; TRICOIRE, H.; CHEMINEAU, P. Biology of mammalian photoperiodism and critical role of pineal gland and melatonin. Journal Biology Rhythms, v. 16, p. 336-347, 2001. 
MARQUES, M. O.; CAMPOS FILHO, E. P.; BARUSELLI, P. S. Efeitos da administração de eCG e de benzoato de estradiol para sincronização da ovulação em vacas Bos taurus X Bos indicus no período pós parto. In: SIMPÒSIO INTERNACIONAL DE REPRODUCCIÓN ANIMAL, 2003, Córdoba. Anais... p.392.

McNEILLY, A. S.; PICTON, H. M.; CAMPBELL, B. K.; BAIRD, D. T. Gonadotrophic control of follicle growth in the ewe. Journal of Reproduction Fertility, Supplement 43, p. 177-186, 1991.

MENCHACA, A.; VILARIÑO, M.; PINCZAK, A. Progesterone treatment, FSH plus eCG, GnRH administration, and Day 0 protocol for MOET programs in sheep. Theriogenology, v. 72, n. 4, p. 477-483, 2009.

MERKLEY, C. M.; PORTER, K. L.; COOLEN, L. M.; HILEMAN, S. M.; BILLINGS, H. J.; DREWS, S.; GOODMAN, R. L.; LEHMAN, M. N. KNDy (Kisspeptin/Neurokinin B/Dynorphin) Neurons Are Activated during Both Pulsatile and Surge Secretion of LH in the Ewe. Endocrinology, v. 153, n. 11, p. 5406-5414, 2012.

MOOR, R. M.; OSBORN, J. C.; CROSBY, I. M. Gonadotrophin induced abnormalities in sheep oocystes after superovulation. Journal Reproduction of Fertility, v.74, p. 167-172, 1985.

MORAES, E. P. B. X. Utilização da ultra-sonografia para diagnosticar alterações uterinas em cabras, gestação, perdas embrionária-fetal e sexo fetal em ovelhas. Medicina Veterinária, v. 1, n. 1, p. 107-108, 2007.

MURPHY, B. D.; MARTINUK, S. P. Equine Chorionic Gonadotrofin. Endocrine Reviews, v. 12, n. 1, p. 27-44, 1991.

NOEL, B.; BISTER, J. L.; PIERQUIN, B.; PAQUAY, R. Effects of FGA and PMSG on follicular growth and LH secretion in Suffolk ewes. Theriogenology, v. 41, n. 3, p. 719-727, 1994.

O`CALLAGHAN, D.; YAAKUB, H.; HYTTEL, P.; SPICER, L. J.; BOLAND, M. Effect of nutrition and superovulation on oocyte morphology, follicular fluid composition and systemic hormone concentration in ewes. Journal Reproduction of Fertility, v. 118, p. 303-313, 2000 .

OLIVEIRA-MUZANTE, J.; FIERRO, S.; LOPEZ, V.; GIL, J. Comparison of prostaglandinand progesterone-based protocols for timed artificial insemination in sheep. Theriogenology, v. 75, p. 1232-1238, 2011.

OWEN, J. B. Breeding for fecundity. Veterinary Record, v. 123, p. 308-310, 1988.

PADILLA-RIVAS, G. R.; SOHNREY, B.; HOLTZ, W. Early pregnancy detection by real time ultrasonography in Boer goats. Small Ruminant Research, v. 58, p. 87-92, 2005.

PIETROSKI, A. C. C. A.; BRANDÃO, F. Z.; SOUZA, J. M. G.; FONSECA, J. F. Short, medium or long-term hormonal treatments for induction of synchronized estrus and ovulation 
in Saanen goats during nonbreeding season. Revista Brasileira de Zootecnia, v, 42, n. 3, p. 168-173, 2013.

PINHEIRO, R. S. B.; SILVA SOBRINHO, A. G.; ANDRADE, E. N. Características quantitativas da carcaça de ovinos de diferentes categorias. Revista Brasileira de Saúde e Produção Animal, v. 10, n. 4, p. 939-948, 2009.

PUGH, D. G. Clínica de ovinos e caprinos. In: MOBINI, S.; HEATH, A. M.; PUGH, D. G. Teriogenologia de ovinos e caprinos. São Paulo: Roca, 2005. p. 145-208.

ROCHA, R. M.; MATOS, M. H. T.; LIMA, L. F.; SARAIVA, M. V. A.; ALVES, A. M. C. V.; RODRIGUES, A. P. R.; FIGUEIREDO, J. R. Melatonina e reprodução animal: implicações na fisiologia ovariana. Acta Veterinaria Brasilica, v. 5, n. 2, p. 147-157, 2011

ROSENFELD, C. S.; WAGNER, J. S.; ROBERTS, R. M.; LUBAHN, D. B. Intraovarian actions of oestrogen. Reproduction, v. 122, n. 2, p. 215-226, 2001.

SANTOS, G. M. G.; SILVA-SANTOS, K. C.; MELO-STERZA, F. A.; MIZUBUTI, I. Y.; MOREIRA, F. B.; SENEDA, M. M. Desempenho reprodutivo de ovelhas mestiças lanadas e deslanadas submetidas a protocolo hormonal a base de progestágeno e eCG, durante a contraestação reprodutiva. Semina: Ciências Agrárias, v. 32, n. 2, p. 723-732, 2011.

SASA, A.; TESTON, D. C.; CRIVELLENTI, T. L.; RODRIGUES, P. A.; SILVA, E.C. F.; COELHO, L. A.; SCHALCH, E. Concentrações Plasmáticas de Progesterona em Borregas Lanadas e Deslanadas Durante o Período de Abril a Novembro no Estado de São Paulo. Revista Brasileira de Zootecnia, v. 31, n. 3, p. 1150-1156, 2002.

SCARAMUZZI, R. J.; ADAMS, N. R.; BAIRD, D.T.; CAMPBELL, B. K.; DOWNING, J. A.; FINDLAY, J. K.; HENDERSON, K. M.; MARTIN, G. B.; McNATTY, K. P.; McNEILLY, A. S. A model for follicle selection and the determination of ovulation rate in the ewe. Reproduction, Fertility and Development, n. 5, p. 459-478, 1993.

SKINNER, D. C.; HARRIS, T. G.; EVANS, N. P. Duration and amplitude of the luteal phase progesterone increment times the estradiol-induced luteinizing hormone surge in ewes.

Biology of Reproduction, v. 63, n. 4, p. 1135-1142, 2000.

SMITH, J. T. The role of kisspeptin and gonadotropin inhibitory hormone in the seasonal regulation of reproduction in sheep. Domestic Animal Endocrinology, v. 43, p. 75-84, 2012.

SOUZA, C. J. H. Dinâmica da ovulação e biologia do ciclo estral em ovelhas 3/4 Romney Marsh X 1/4 Merino Booroola portadoras ou não de um gene principal determinante de prolificidade. 1993. 58f. Dissertação de Mestrado - Faculdade de Veterinária, Universidade Federal do Rio Grande do Sul, 1993.

UNGERFELD, R.; RUBIANES, E. Effectiveness of short-term progestogen primings for the induction of fertile oestrus with eCG in ewes during late seasonal anoestrus. Animal Science, v. 68, p. 349-353, 1999.

VANECEK, J. Cellular mechanisms of melatonin action. Physiological Research, v. 78, p. 687-721, 1998. 
VIANA, J. G. A. Panorama geral da ovinocultura no mundo e no Brasil. Revista Ovinos, v. 12, p. 1, 2008.

VIANA, J. G. A.; SILVEIRA, V. C. P. Análise econômica da ovinocultura: estudo de caso na Metade Sul do Rio Grande do Sul, Brasil. Ciência Rural, v. 39, n. 4, p. 1187-1192, 2009.

VIANA, J. G. A.; REVILLION, J. P. P.; SILVEIRA, V. C. P. Alternativa de estruturação da cadeia de valor da ovinocultura no Rio Grande do Sul. Revista Brasileira de Gestão e Desenvolvimento Regional, v. 9, n. 1, p. 187-210, 2013.

VILLAROEL, A. B. S.; LIMA, L. E. S.; OLIVEIRA, S. M. P.; FERNANDES, A. A. O. Ganho de peso e rendimento de carcaça em cordeiros mestiços Texel e Santa Inês x SRD em sistema de manejo semi-intensivo. Ciência e Agrotecnologia, v. 30, n. 5, p. 971-976, 2006.

VILARIÑO, M.; RUBIANES, E.; VAN LIER, E.; MENCHACA, A. Serum concentrations, follicular developmente and time of ovulation using a new progesterone releasing device (DICO®) in sheep. Small Ruminant Research, v. 91, p. 219-224, 2010.

VILARIÑO, M.; RUBIANES, E.; MENCHACA, A. Re-use of intravaginal progesterone devices associated with the short-term protocol for timed artificial insemination in goats. Theriogenology, v. 75, p. 1195-1200, 2011.

VILARIÑO, M.; RUBIANES, E.; MENCHACA, A. Ovarian responses and pregnancy rate with previously used intravaginal progesterone releasing devices for fixed-time artificial insemination in sheep. Theriogenology, v. 79, p. 206-210, 2013.

VINÕLES, C.; MEIKLE, A.; FORSBERG, M.; RUBIANES, E. The effect of subluteal levels of exogenous progesterone on follicular dynamics and endocrine patterns during the early luteal phase of the ewe. Theriogenology, v. 51, p. 1351-1361, 1999.

VINÕLES, C.; FORSBERG, M.; BANCHERO, G.; RUBIANES, E. Effect of long-term and short-term progestagen treatment on follicular development and pregnancy rate in cyclic ewes. Theriogenology, v. 55, n. 1, p. 993-1004, 2001.

WHEATON, J. E.; CARLSON, K. M.; WINDELS, H. F.; JOHNSTON, L. J. CIDR: A new progesterone-realising intravaginal device for induction of estrus and cycle control in sheep and goats. Animal Reproduction Science, v. 33, p. 127-141, 1993. 